\title{
POR UNA ARQUITECTURA APROPIADA Y APROPIABLE
}

\author{
(IN SEARCH OF APPROPRIATE AND ADAPTABLE ARCHITECTURE) \\ C. González Lobo, Arquitecto
}

$127-26$

\section{RESUMEN}

Se exponen en el presente artículo ideas y métodos de construcción que pueden ser fácilmente aplicables en los paises en vias de desarrollo. Se realiza una pormenorizada exposición de distintos sistemas de autoconstrucción de cubiertas que resuelven algunos de los problemas más frecuentes en las viviendas.
SUMMARY

The article expounds construction ideas and methods easily applied to underdeveloped countries. Different systems of auto-construction of roofs, which solve some of the most common problems in housing, are examined in detail.

\section{Mulieres opulentxe furgite, $\&$ audite vocem meain. Poft dies, $\mathcal{S}^{\prime}$ annum, $\&$ vos conture bemini.}

$$
\text { ISXIE XXXII }
$$

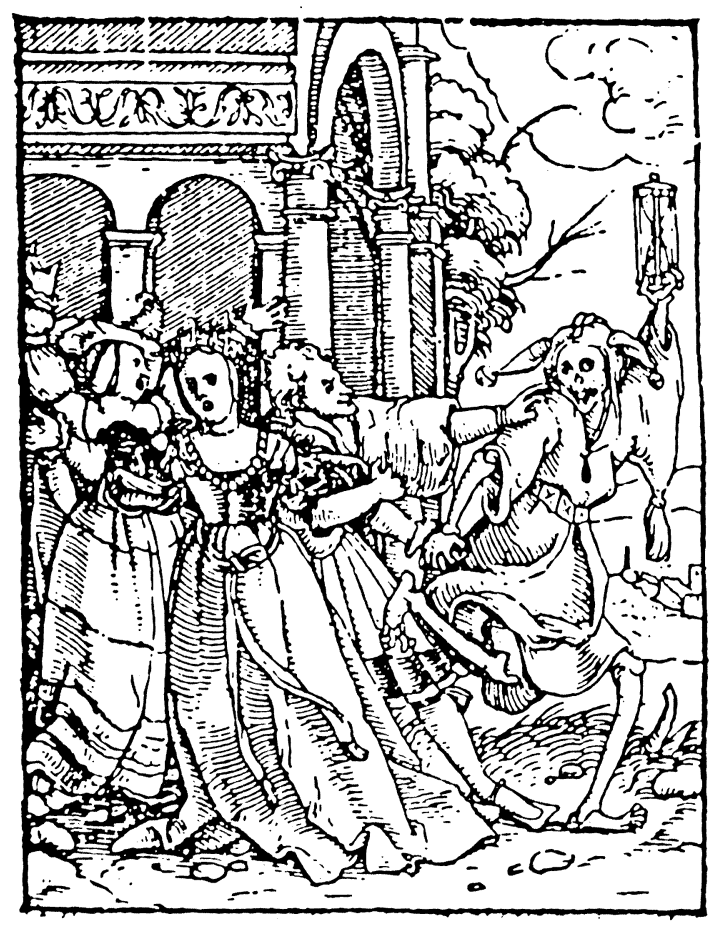

“...Un fantasma recorre los caminos de la arquitectura moderna, tranformándola desde sus raices: el fantasma de las necesidades del tercer mundo, del mundo subdesarrollado, tricontinental..."

Arq. Fernando Salinas: Arquitectura Revolucionaria del Tercer Mundo.

A trece años del fin del milenio, nuestros paises: latinoamericanos, africanos y asiáticos, y aún las amplias masas de población pobre de los paises capitalistas desarrollados (también hay "tercer mundo" en New York) tenemos ante los ojos necesidades imperativas que a la luz de la crisis de la Economía-MundoCapitalista, son inalcanzables.

Las soluciones que nos ofrecen las teorias arquitectónicas con origen en el "Mundo Desarrollado", a saber: a) El funcionalismo-racionalista; y b) Las críticas evocativas y lingüisticas que hace el mal denominado post-modernismo, a la arquitectura de corte funcionalista "moderna" no nos ofrecen hoy un apoyo alternativo realmente aplicable al crecimiento de la demanda espacial habitable; a las carencias acumuladas, en materia de vivienda, servicios e infraestructura, al deterioro involutivo del patrimonio construido (histórico) y a las restricciones que en materia de gasto social, impone el Fondo Monetario Internacional a los Gobiernos de nuestros paises, con una deuda externa impagable. 


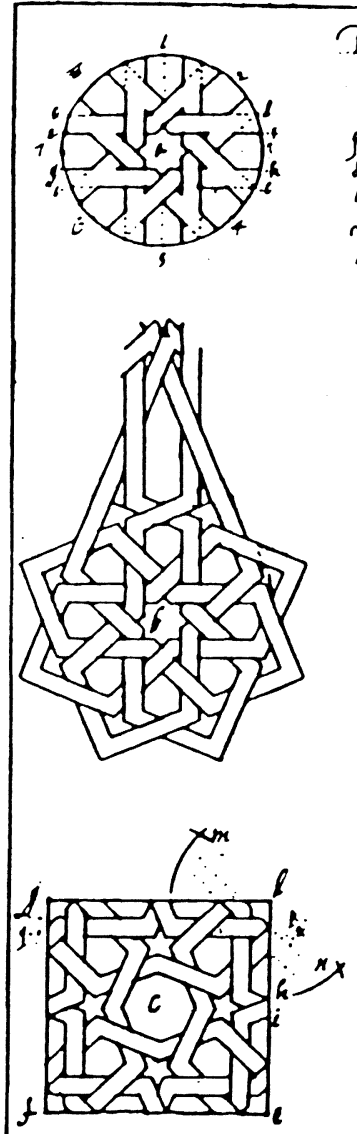

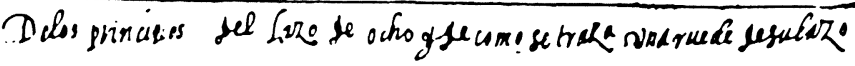

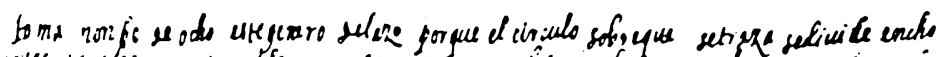

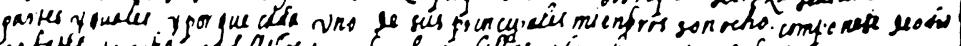

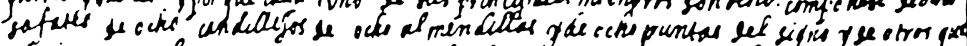

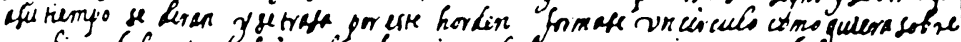

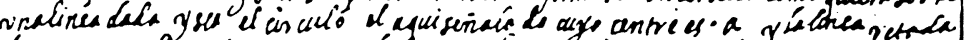

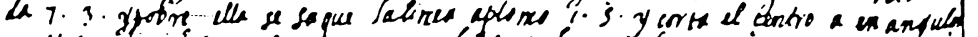

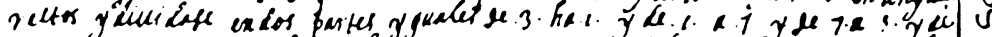

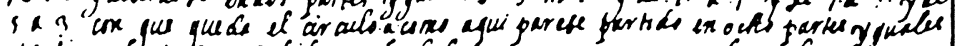

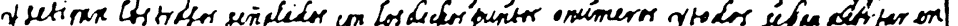

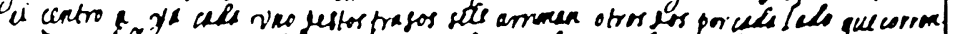

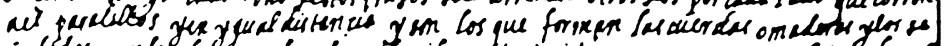

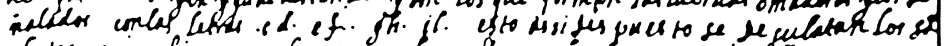

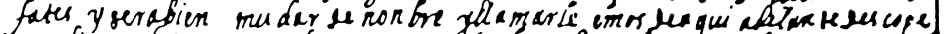

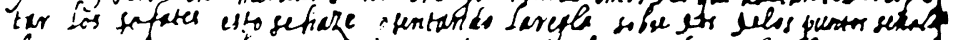

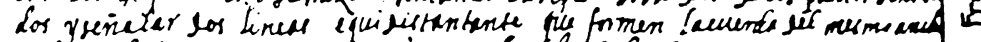

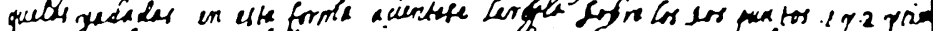

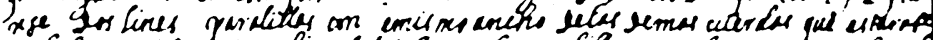

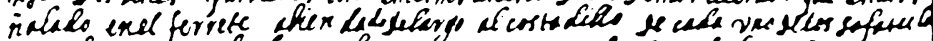

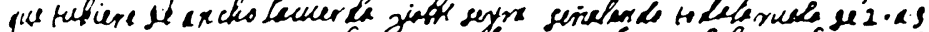

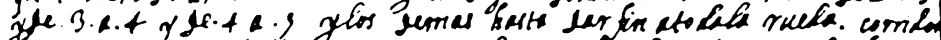

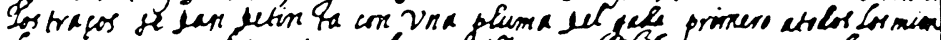

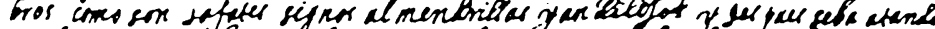

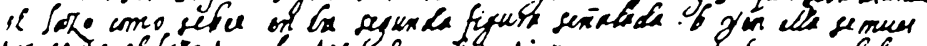

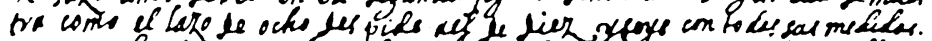

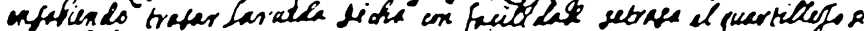

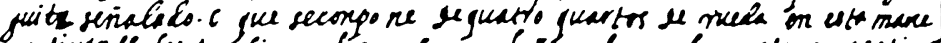

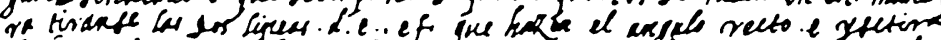

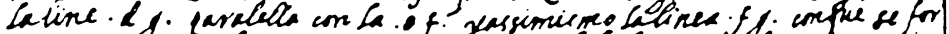

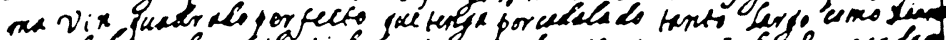

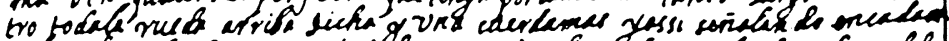

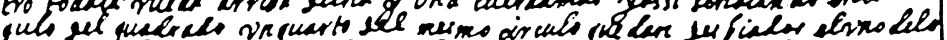

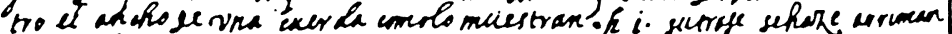

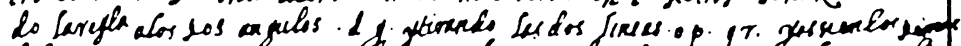

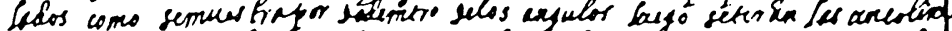

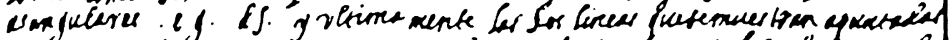

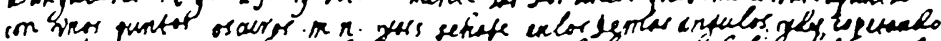

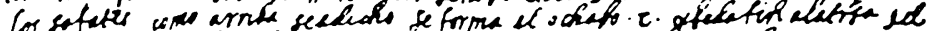

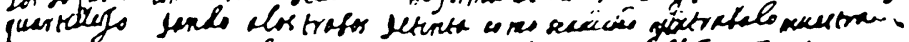

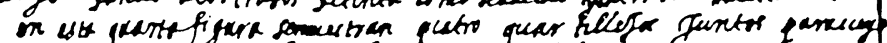

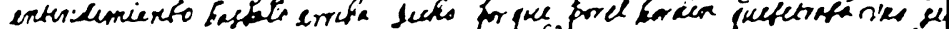

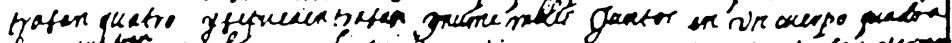

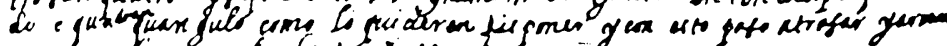

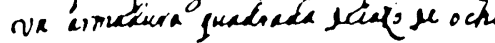

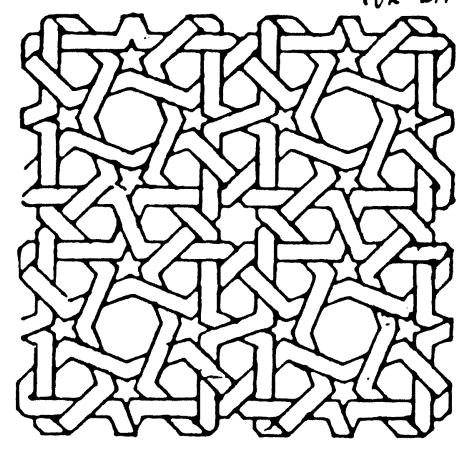

Por una Arquitectura Apropiada y Apropiable

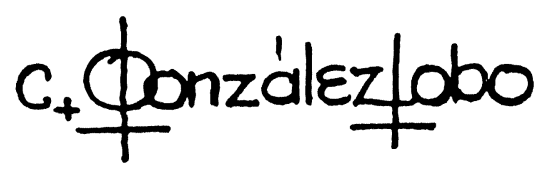


Ante esta carencia teórica y para enfrentar las circunstancias expuestas nos vemos obligados a construir, desde nuestros ámbitos académicos, profesionales y de trabajo, de los que se reclaman solidarios con los más necesitados, una teorización arquitectónica vinculada a la experimentación práctica coyuntural y a la investigación sistemática en materia de producción arquitectónica y urbana. Es una búsqueda de sistemas, hipótesis y modos de trabajo que anuncien, en las tinieblas alienantes del último tercio del siglo veinte, la aurora de una cultura "verdaderamente humana" que integre los avances científicos culturales y tecnológicos más avanzados por un lado y con la cultura, situación y recursos reales que las mayorías necesitadas de nuestros paises tienen, por el otro. Exigencias espaciales, que se tornan progresivamente, elementos de una lucha por el acceso, a la elevación de "su" calidad de vida, por lo menos de sobrevivencia, pero con esperanzas ciertas de un futuro mejor y generan esta búsqueda, incipiente y lenta, pero firme hacia definir un quehacer arquitectónico que se constituya como apoyo solidario de los sectores populares independientes, en su gestión por su techo y "su ciudad" (la nuestra, en rigor).

Es una teoria que busca y admite una Arquitectura Pobre (1), pero que reivindica, y se construye por y para la comunidad, en medio de sus luchas por organizarse independientes y ser historia. Por ello, construcción de un espacio y su entorno a) En que con recursos mínimos ylo escasos, se pueda lograr una "calidad habitable", que integre y albergue las modalidades regionales de usos, hábitos y costumbres de la población; b) Que supere la contradicción entre necesidades espaciales máximas y posibilidades escasas y precarias; c) Que además incorpore las soluciones constructivas, espaciales y poéticas, mas avanzadas, logradas por el desarrollo de la humanidad. Arquitectura pobre en recursos, pero rica en sugerencias y experiencias espaciales y ambientales, que recuperan la "habitabilidad de los usuarios", como centro de interés y motivo de la poética espacial en los sistemas proyectuales.

Ahora bien, si esto se nos presenta como proyecto necesario y deseable, su construcción parece estar en un camino lleno de precariedad y de contradicciones ideológicas y teóricas; y además en clara disyunción con las sendas del éxito profesional, comercial y de "reconocimiento" de la cultura arquitectónica oficial, en nuestro medio.

Este proyecto se va construyendo sin embargo. Por múltiples grupos colectivos de trabajo: grupos de técnicos independientes y grupos de universitarios progresistas que, entre nosotros, abarcan casi todos los paises

(1) Uso aqui el término arquitectura pobre en el mismo sentido que Jersy Grotowsky teorizó en su "Teatro Pobre". latinoamericanos, aunque sus experiencias, investigaciones y hallazgos, sólo son conocidas en los ámbitos inmediatos a los productores y los usuarios beneficiados.

Este artículo no recoge, ni resume, lamentablemente esta Construcción teórica, proyectual, organizativa y productiva; ésta es un producto cultural "in nuce", cuya magnitud hoy desconozco, pero que seguramente se realizará progresivamente por los actores de este proceso, en un futuro que espero próximo, y que este texto espera propiciar. Sin embargo además de enunciar la problemática y ofrecer mis observaciones teóricas provisionales creo que debemos aportar nuestro urgente esfuerzo para lograrlo.

La experiencia que voy a mostrar, vinculada a esa teoría incipiente, y que siento poder afirmar con alguna seguridad, es la de algunas de mis innovaciones en materia de sistemas constructivos y alternativos: los cascarones de hormigón armado, sin cimbra, sobre metal desplegado y las cubiertas de barro armado realizadas por prefabricación popular cooperativa; que desde 1958 y 1980 respectivamente, vengo construyendo en trabajos profesionales, ligados a grupos de pobladores sin recursos y realizadas tanto en provincia, como en zonas rurales y en las colonias "marginales" de la periferia y el centro de la ciudad de México. Lo muestro así, en razón de la brevedad de este artículo, ya que en rigor la experiencia sólo hace sentido e integra: a) La práctica del diseño participatorio con grupos autogestivos de constructores populares; b) La aplicación de sistemas proyectuales: de familias de prototipos, de lotificación densa con urbanización mínima, y los que permitan la flexibilidad y los crecimientos progresivos de la obra; y c) La construcción en base a tecnologías perdurables, de bajo costo, apropiadas a las necesidades espaciales y apropiables por los usuarios (en su proceso de autogestión) sin requerir de mano de obra especializada y equipos sofísticados de construcción.

Pero lo publico también para suscitar el interés por la difusión y extensión de estos modos del "hacer", entre los arquitectos y grupos fraternos, técnicos y politicos vinculados a la lucha por el techo de los pobladores pobres.

Dividiré este trabajo en dos partes, no necesariamente sucesivas: la descripción de la reflexión sobre las cubiertas económicas sin el uso de cimbra, y la descripción sucinta de algunas experiencias proyectuales concretas en que aplique estas tecnologías y que muestran por un lado su capacidad para adecuarse a los problemas arquitectónicos y constructivos, así como su aceptación y reproducción en manos de los usuarios.

En esta primera parte, muestro dos sistemas constructivos, que se pretenden apropiados y apropiables, tan- 
to para la construcción arquitectónica de los pobres y como un elemento en la lucha de resistencia cultural, política y económica, que las clases explotadas de nuestros países tienen que dar, ahora y en el futuro inmediato.

Para ellos, los sistemas tecnológicos deben cumplir dos grupos de requisitos: en primer término, dar apoyo a la práctica proyectual (hoy marginal) y las investigaciones arquitectónicas y urbanas que en apoyo solidario con los sectores pobres (organizados e independientes) vienen realizando grupos de profesionales y de universitarios en nuestros países ( $y$ a los que se acostumbra llamar: grupos técnicos solidarios); y por ello que dicha práctica se realiza para atender a sectores de usuarios pobres, para realizarse en áreas urbanas y rurales pobres y en paises pobres.

En segundo término que dicha práctica pretende apoyar y fortalecer una práctica cultural y política de resistencia ante una situación cultural, política y económica de la llamada "crisis", palabra que encubre la real explotación intensificada del pueblo trabajador, la carestía y la disminución real del salario y en medio de un empobrecimiento progresivo y constante, en nuestros países: capitalistas, subdesarrollados y dependientes. Que enfrenta a los grupos organizados populares, con una dirección política nacional autoritaria y burocrática, con una cultura trasnacional basada en impulsar el consumo dirigido y manipulada por los medios masivos de comunicación que genera un deterioro de la cultura nacional tradicional, que se ve suplantada por una "dependencia arrobada" a los modos "taiwanizados" de la cultura hegemónica imperial norteamericana.

Ante la evidente imposibilidad de atender la satisfacción de las demandas espaciales-habitables de los grupos mayoritarios pobres, empleando las tecnologías más eficientes y avanzadas, ya que estas tecnologias son aprovechadas por las empresas de la construcción y las constructoras, para capitalizar los beneficios económicos de las mismas, he dirigido mis esfuerzos a la exploración de tecnologías "alternativas", aplicables al proyecto de una arquitectura pobre. Buscamos por tanto las que reduzcan el costo, que sean apropiadas a la demanda espacial tanto estricta como a la sentida; por tanto: por ser accesibles a las posibilidades reales de los usuarios necesitados, como por ser: amplias, perdurables y resistentes ("de material", se dice en nuestras colonias populares), y que además de una buena "presentación" formal sean seguras y que "garanticen" la permanencia de la obra y con ello la del usuario en el lugar. Y por último que sea una tecnología apropiable por los usuarios, en procesos de autoconstrucción o de realización con mano de obra sin calificación específica. Son tecnologias alternativas, apropiadas al caso concreto y apropiables por el usuario.

\section{LA INVESTIGACION TECNOLOGICA: APROPIADA Y APROPIABLE}

Como todos sabemos, es la cubierta o techo, uno de los puntos de mayor dificultad en la construcción de la vivienda pobre. Dos parecen ser las dificultades esenciales: el alto costo de los materiales eficientes y pres. tigiados (reconocidos como los que se usan para la clase dominante) por un lado, y la ejecución técnica de la techumbre que requiere de "maestria": conocimiento específico, experiencia constructiva y la ocupación de equipos costosos de obra falsa: cimbras, tendidos, etc. Por ello la solución "pobre" a la techumbre generalmente es de: láminas de desecho, cartón asfáltico, lámina acanalada "de zinc" sobre listones sencillos de madera, esto en las ciudades; en las zonas rurales se usa la palapa, el guano o la paja sobre morillos y varas. Con esto el techo es sumamente "provisional", no es higiénico y aun costoso actualmente; un temporal, un sis. mo o la fuerza pública, los deshacen fácilmente. De ahi surge la demanda necesitada y sentida de que la techumbre sea: perdurable, resistente, segura, impermeable y que permita el crecimiento sobre ella a un segundo piso; esto en México parece lograrse con la solución de losa maciza, de hormigón reforzado. Pero esta solución deseable es cara; tanto por el costo del hormigón, del acero y por el uso de cimbra.

Por esto enfoqué mis búsquedas a superar la contradicción enunciada: una techumbre que sea "de material" con todas sus virtudes, pero que reduzca el costo de ejecución y de los costos en materiales industrializados como cemento y acero y el costo adicional de la cimbra. Con objeto de explicar con mayor profundidad esta reflexión, veamos las condiciones que se presentaron:

\section{La necesidad de una tecnología apropiada}

El primer problema que se me presentó, era la necesidad de lograr un techo de bajo costo y que además ha de realizarse con mano de obra que mayoritariamente carece de capacitación específica y contando en el mejor de los casos con la dirección de un oficial albañil e hipotéticamente la asesoría de un grupo técnico solidario (profesional o universitario); por ello necesitamos evitar en el sistema constructivo, que el problema reclama como apropiado al caso, la construcción que requiera mano de obra especializada, uso de equipo "sofisticado" como cimbras, tendidos, plumas o malacates, que por su costo se hacen prohibitivas.

Además la tecnología debe ser lo suficientemente versátil para ajustarse a los más variados tamaños, destinos, materiales disponibles y al uso de equipo de apoyo mínimo e improvisado. Por último, que la tecnología sea una alternativa que recoja la tendencia implíci- 
ta en la demanda de los usuarios, que nos piden: ¿Y si además de barata y fácil, fuera amplia, espaciosa... y bonita?; por lo tanto la pregunta se define como una búsqueda de una tecnología de construcción de cubiertas: de "material" (duradero) y apropiada para ser realizada por mano de obra sin calificación, con un mínimo de asesoría técnica, versátil, en diversos materiales disponibles, que requiera equipo sencillo de construcción y que siendo muy económica, ofrezca amplitud y una calidad expresiva atractiva.

\section{La necesidad de una tecnología apropiable}

El segundo problema consistió en encontrar una tecnología alternativa basada en que puedan apropiársela fácilmente los usuarios, quienes no sólo no son constructores, sino además, han sido sujetos de un proceso de alienación histórico, constante y programado; debería ser una tecnología "para ellos", que les facilite hacer la obra y que desarrolle a través de su aprendizaje y práctica una comprensión y desarrollo de ellos como sujetos transformadores, que se extienda después a otras actividades... ojalá.

Esto exige por lo menos que la tecnología cumpla las siguientes consideraciones: que se la pueda usar mediante un rápido aprendizaje, sencillo y con pocas metas; que no exija ni el manejo, ni la posesión de equipo de construcción sofisticado (para los habitantes de una colonia popular por ejemplo); que permita e induzca a la colaboración en el trabajo, ya que esto aglutina, solidariza y fortalece a la escasa o incipiente organización autogestiva; que se adapte a los ritmos y tiempos de cada circunstancia o disposición del grupo para construir por: faenas, tequios, los fines de semana, en jornadas de trabajo nocturno, etc.; y además que integre a todos como mano de obra los ancianos, los niños, las señoras, los jóvenes, etc. Por tanto la pregunta se define como la necesidad de que la tecnología sea una alternativa tal, que se la apropien fácilmente los potenciales usuarios, pese a su desorganización, incultura y egoísmo, de manera que la tecnología apoye al grupo autogestivo tanto para obtener el satisfactor a sus necesidades, como centralmente coadyudar a los usuarios a capacitarse y verse como sujetos que son capaces de hacer... su historia.

\section{De cómo acceder a una cubierta de bajo costo}

Dos fueron las cuestiones que indicaron cómo solucionar el problema de la techumbre: el uso de las nuevas geometrias estructurales para concebir una bóveda, y la eliminación del uso de la cimbra.

La losa maciza de hormigón armado a la que señalamos antes como el paradigma para los constructores popu- lares, cierra con el mínimo volumen interno (habitable), que estará definido por la altura del enrase de los muros; pero además requiere para construirla de más hormigón y acero de refuerzo ya que por su geometría estructural con el máximo momento en el centro, que se "toma" a base de reforzar con acero estructural y aumentar la sección de la losa en hormigón.

En cambio la superficie abovedada, nos ofrece una cubierta que incrementa (parece "inflar"), el volumen espacial habitable, que ya no se define por el enrase de los muros que serían los mismos que para el ejemplo de la losa maciza; pero además permite reducir las cantidades de hormigón y acero; el hormigón por el espesor de la cubierta (de cascarón) y por la reducción mínima del refuerzo de acero estructural, ya que los esfuerzos se transmiten fundamentalmente a compresión a través del cuerpo de la bóveda. Tiene sin embargo esta solución dos limitaciones graves que la han hecho incosteable hasta ahora: por un lado, los esfuerzos adicionales horizontales que generan las bóvedas Ilamados coceos, y por otro que la construcción de la bóveda es de difícil trazo y muy costosa la construcción de obra falsa para encofrar (cimbra como de ebanisteria).

\section{SISTEMA CGL-1:}

\section{Bóvedas de hormigón armado, sin cimbra}

El procedimiento que desarrollé, superó estas limitaciones mediante la integración de: a) El concepto estructural del Ingeniero español E. Torroja (2) sobre las vigas dípteras para la construcción de láminas cilíndricas que: elimina el coceo y liberan los arranques de la bóveda (la cara de las generatrices), de transmitir esfuerzos al suelo; y b) Eliminando la cimbra en el colado del hormigón armado, mediante la colocación de metal desplegado ligero, "bajo" el armado de acero (3) y colando con hormigón de bajo revenimiento 0.03 (como una mantequilla).

El sistema se constituye asi en la definición de un método constructivo-proyectual alternativo apropiado y apropiable, para producir techumbres de bajo costo y de máxima capacidad espacial interna.

(2) Ing. Eduardo Torroja - Razón y Ser de las Formas Estructurales, Madrid. Ed. Taurus, ver la pág. 116 y siguientes; o la ilustración de su frontón de Recoletos, en Madrid 1935, en Jurgen Joedike. Shell Architecture, Ed. A. Tiranti, London 1963, pág. 68.

(3) Para mayor precisión sobre el sistema propuesto puede consul tarse el artículo Bóvedas de Concreto Armado sin cimbra, del autor en la revista: Arquitectura-Autogobierno Nos. 5 y 6 (marzo a junio) 1977, UNAM, México. 


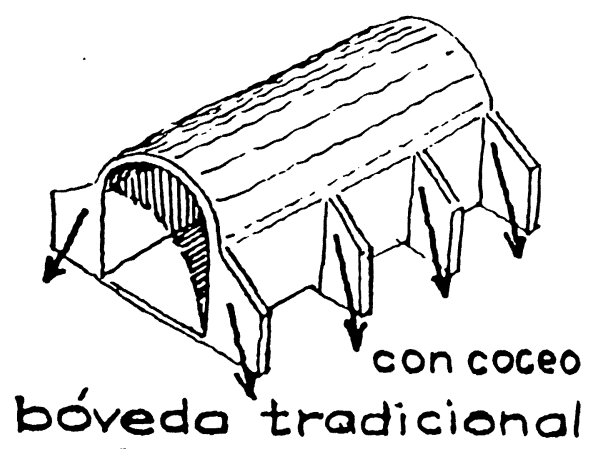

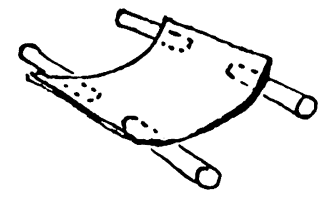
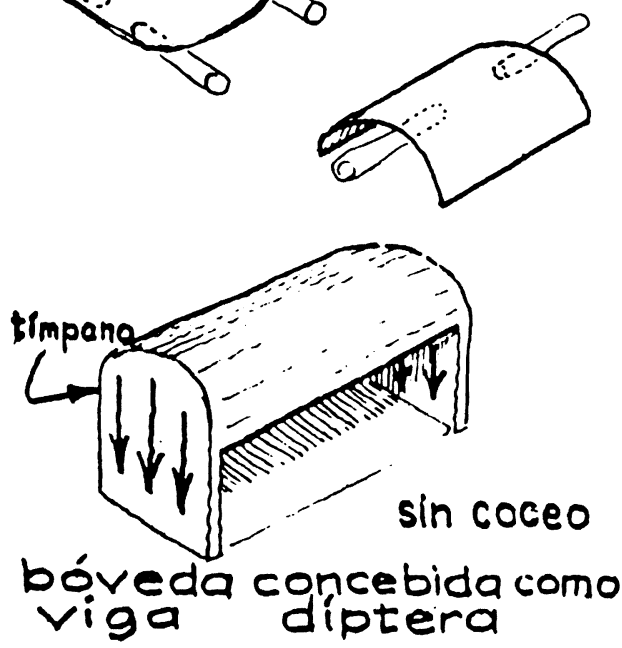

\section{Descripción del procedimiento de construcción}

Se procede en general asi: Se calcula el trazo del muro de tímpano, tal que no rebase la relación flechaancho de 1:7 (la más económica es de 1:5); sobre los muros del enrase conveniente (mínimo 2,10) se coloca una cadena perimetral; se cuela sólo en los lados cortos (los tímpanos) y encima se construyen éstos. Es conveniente dejar huecos en tres lados de cada tímpano (mechinales), para pasar por ellos las tres vigas o morillos que soportarán el armado y el hormigón fresco. Se traza en el piso la curva de las directrices de la bó. veda y ahí se doblan las varillas necesarias. Se colo. can sobre los morillos, con una separación mínima de $0,50 \mathrm{~m}$ ( $\varnothing 3 / 8$ "). Sobre ellas se colocan las varillas rectas "generatrices", con la misma separación y diámetro y se amarran. Y ya está terminada la armazón de la bóveda. Se colocan luego los refuerzos (determinados por el cálculo) por encima. Bajo la armazón, se despliega el rollo de metal desplegado y se lo amarra, dejando translapes de $10 \mathrm{~cm}$. Se colocan 2 puntales de polín (o morillo) por viga, y se les contraventea con torzales de alambre retorcido o tablas. Se procede al colado, empleando hormigón 1:2:3 con árido grueso de $3 / 4$ " $\varnothing$ (confitillo), con un espesor de $0,04 \mathrm{~m}$ sobre el metal desplegado y regleándolo o aplanándolo según las generatrices (rectas). En las cadenas del arranque de las bóvedas se forjan las canaletas para la lluvia, y se dejan empotrados alambrones para las gárgolas. Se cura el hormigón durante 3 días y se aplana por las dos superficies, lográndose una cáscara de 0,06 m (mínimo) monolítica y con su acabado integral; esta cubierta se puede impermeabilizar con varios métodos, son muy resistentes si al aplanado superior se le agrega impermeabilizante integral. Las bajadas de agua pluvial se resuelven dando las pendientes necesarias a los canalones laterales y bajándola al suelo por gárgolas, cadenas o bajadas de tubería; para càrgar los tinacos, se refuerza el área de descarga de' los muretes con bastones de $120 \varnothing$ (de $3 / 8$ ") y se deja rugoso el hormigón para lograr la adherencia de los muretes.

Con este sistema constructivo CGL-1, se pueden realizar además todo tipo de cubiertas de diversas geometrías y hasta esculturas. Esto se ha experimentado y construido con eficiencia suficiente en el cascarón de la Iglesia del Mirasol, que es de $14 \times 25 \mathrm{~m}$ y pasó por las pruebas sísmicas, sin daño alguno, incluyendo la del 19 de septiembre del 85; desde 1959 a la fecha (4) ya son 28 años lo que estas estructuras siguen en uso, construidas con mano de obra sin calificación espe. cial y con un costo mínimo y competitivo; e inclusive hemos desarrollado la posibilidad de que las bóvedas sean armadas y forjadas en el piso (prefabricado en sitio) y luego izadas, enderezadas y coladas (5). Con ello podemos usar la mano de obra que puede trabajar en el suelo y no podria hacerlo sobre andamios y tendidos.

(4) Las primeras notas sobre el procedimiento aparecen en Remodelación de Comunidades Rurales: Tesis profesional de Carlos González Lobo. Escuela Nacional de Arquitectura. UNAM. 1963.

(5) En relación a esta modalidad quiero consignar el trabajo del Arquitecto Miguel Angel Bautista, quien construye con este méto do escuelas en el estado de Oaxaca. y las que presente en el prototipo 85 de vivienda unifamiliar de FIVIDESU DEL D.D.F. 


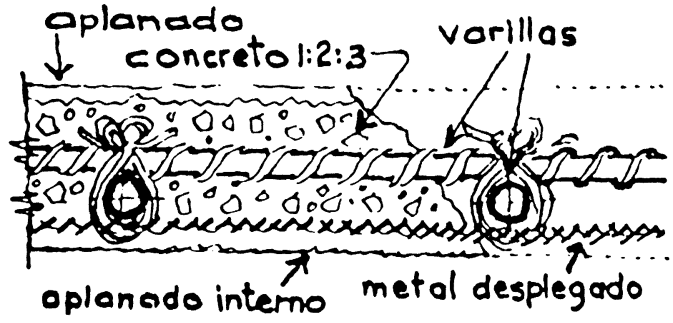

sección típica de la bóveda

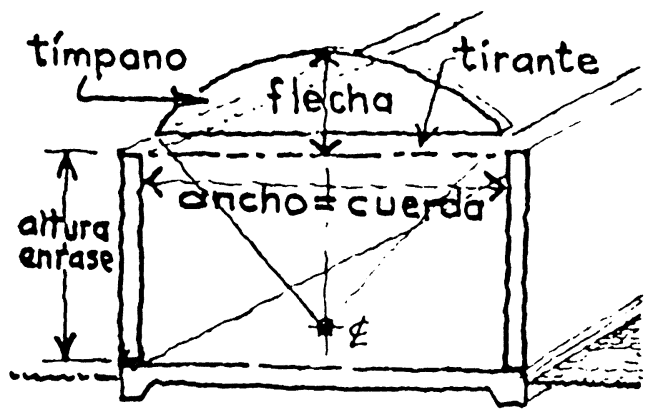

definiciones del sist. constructivo
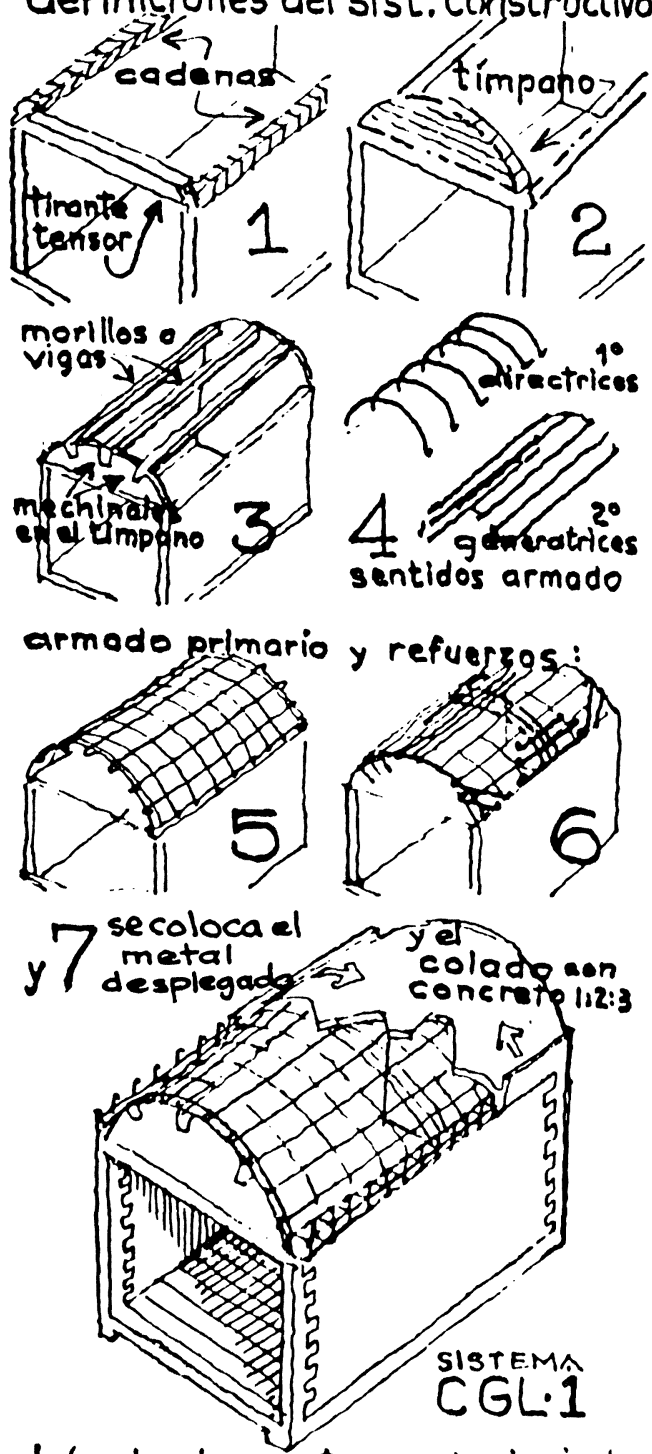

bóvedas de conereto armado sin cimbra

\section{Bóvedas y piezas prefabricadas a pie de obra}

Como un segundo modo de aprovechar el sistema de hormigón sin cimbra sobre metal desplegado, para usar la fuerza de trabajo que no podría trabajar en condiciones de seguridad en lo alto de los andamios, amarrando y desplegando el rollo de metal, reduciendo además el tiempo de realización de este trabajo, hemos desarrollado un método de prefabricación del armazón metálico en el suelo; y luego lo izamos y unimos a las cadenas y castillos de refuerzo, colándolo como el procedimiento anterior y con iguales resultados (6).

- En este caso se forja un molde de tierra y cascotes en el piso, en la cercanía de la obra con la geometría de la bóveda propuesta, se aplana con una mezcla de cemento-arena en proporción 1:5, a este molde lo llamamos "burro".

- Sobre el molde se colocan las varillas directrices (curvas) previamente moldeadas en un trazo en el piso, con una separación de 0,70 metros.

- Encima de las varillas directrices se colocan las varillas rectas (generatrices) con una separación similar, y se amarran con alambre recocido.

- Se coloca sobre este armazón primario, malla electro-soldada 10-10, 10-10, con translapes entre las secciones de malla de 2 cuadros.

- Por encima se colocan los refuerzos que nos indica el cálculo específico: las cruces ortogonales, las cruces diagonales, los refuerzos a $45^{\circ}$ en las esquinas y las parábolas para el flambeo en los centros de arranque, y se forjan los tímpanos o tirantes, amarrando con alambre el armazón conjunto.

- Se saca el armazón del molde, volteándolo como una lancha y se coloca en su interior el metal desplegado n. $^{\circ} 500$.

- Se iza a ocupar su puesto encima de los muros y soportes verticales y se procede a unir las puntas de los castillos o columnas con la armazón prearmada, uniéndose también a las cadenas de liga sobre los muros o en los bordes.

- Se procede al colado como en el caso anterior.

Este procedimiento lo he experimentado varias veces, incluso en un programa de vivienda en el Pedregoso Sn. Juan del Río Qro, con resultados muy satisfactorios; pero, quiero consignar especialmente su uso en

(6) Las primeras notas sobre el procedimiento aparecen en Remode lación de Comunidades Rurales: Tesis profesional de Carlos González Lobo, Escuela Nacional de Arquitectura, UNAM, 1963. 

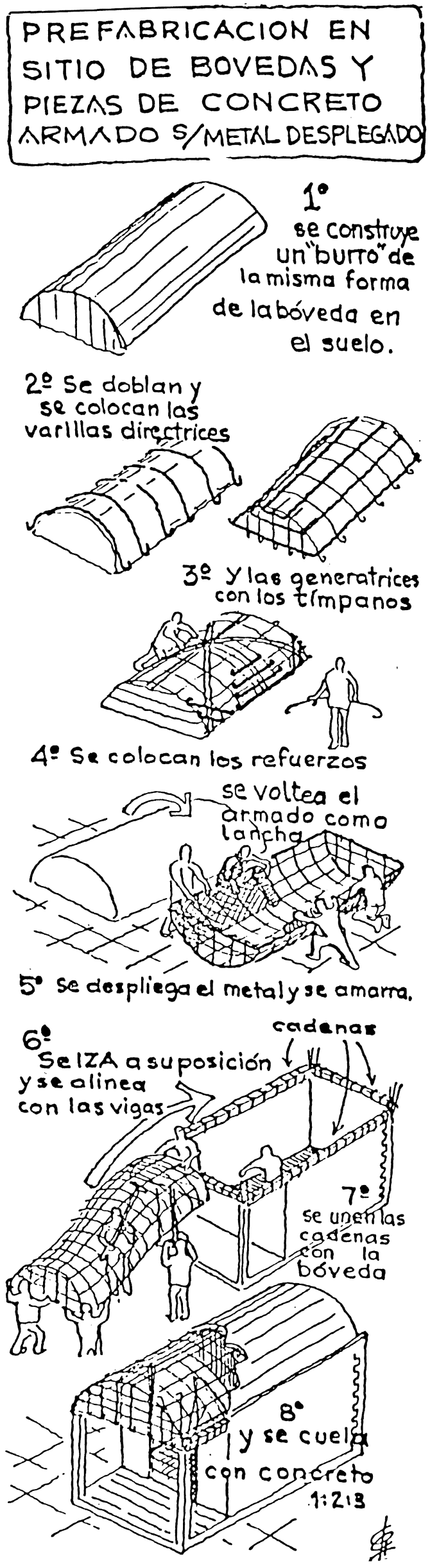

la construcción de escuelas por autoconstrucción en el Estado de Oaxaca, que ha desarrollado brillantemente el Arq. Miguel Angel Bautista Reyes, quien ha realizado la escuela completa incluyendo los muros con este procedimiento (7).

También hemos usado este procedimiento de pre-armar en el piso con otras piezas que facilitan y abaratan la construcción popular.

Las escaleras son generalmente una pieza costosa por su dificultad de construcción y el tiempo que demanda su ejecución; muestro aquí una manera sumamente rápida y eficiente de aplicar el procedimiento, ya que la única forma que requiere de trazo cuidadoso, se hace en un trazo maestro en el suelo y con una grifa y un tubo; se doblan las varillas de $\varnothing 3 / 8$ " ó $5 / 16$ " y se logran escaleras con mínimo material y volumen ocupado que son autoportantes, incluyendo el barandal.

Se pueden hacer de cualquier geometría, incluso en las vecindades de la Col. Guerrero y Morelos las hemos realizado de "mazorca" y media vuelta (una variante de la escalera holandesa).

Sólo para mostrar la riqueza de usos que permite el procedimiento señalo su uso para muros estructurales de separación, en que se pueden realizar ventanas especiales, muebles integrados; muros curvos, alabeados, etcétera.

En este caso es importante armar el muro con una cuadrícula mínima de $0,20 \times 0,20 \mathrm{~m}$, amarrar el metal des. plegado por un lado y colar en dos tiempos: primero con "pellas" de mezcla de cemento-arena 1:3 y dejar que fragüe, aunque no llene toda la superficie. Sobre el hormigón fraguado se procede a aplanar con mezcla 1:6. Los muros o mamparas pueden tener desde 0,025 a $0,04 \mathrm{~m}$. Con estos procedimientos de pre-armado y colado podemos hacer por ejemplo: lucernarios o lucarnas (lunetos) en las bóvedas, muebles de hormigón armado y closets o guardarropas que emerjan en la fachada para una mayor ocupación del espacio de la recámara. También con este procedimiento hemos construido muros para el baño de uso múltiple y simultáneo ya que cualquier geometria es viable con este método.

(7) Además del Arq. M. A. Bautista ha elaborado un sistema construc tivo en base a Adobe de tierra reforzado con alambre de puas. en el medio rural, con resultados muy satisfactorios. que ojalá sean publicados próximamente. 
USOS dol sistema CGL-1

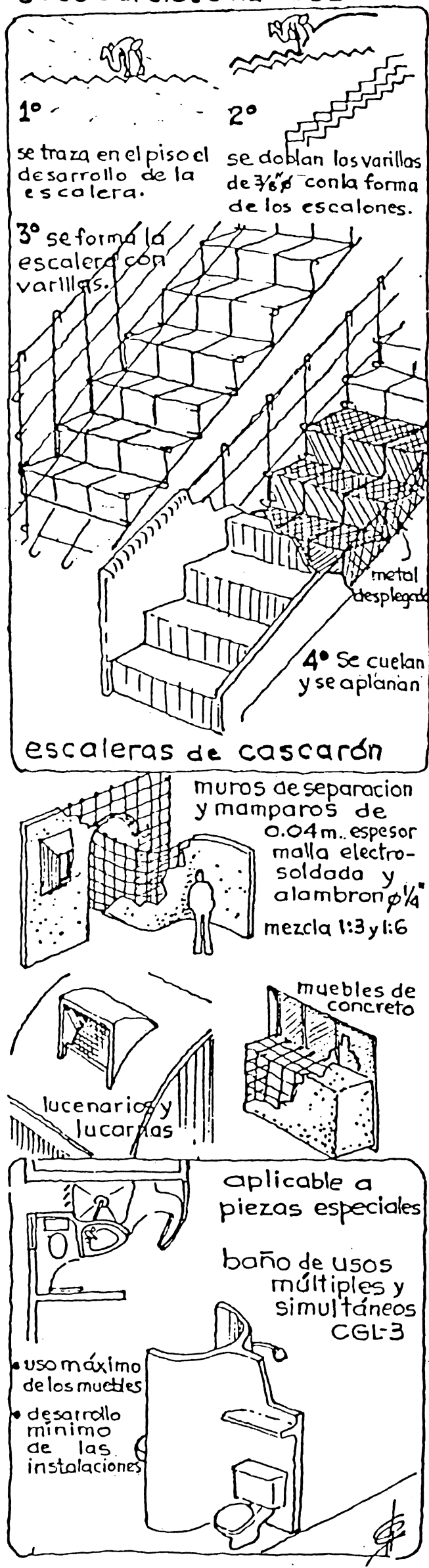

$1^{\mathrm{e}}$. argumento: Espacio máximo y Costo mínimo. Con objeto de garantizar las ventajas económicas de mi procedimiento, introduciré aquí un análisis comparativo entre la losa maciza de hormigón armado y la bóveda díptera de hormigón armado sobre metal desplegado (sin cimbra) sistema CGL-1.

Así vemos, cómo usando este sistema tecnológico alternativo podemos construir un espacio máximo: $21 \%$ más de volumen habitable; y con un costo mínimo: ahorrando el $34 \%$ en hormigón, $42 \%$ en acero y un $65 \%$ del costo de la cimbra; lo que en términos de "apropiado" al autoconstructor de escasos recursos, es una solución que "potencia" su posibilidad estricta de techar... y "material" como lo demandan los usuarios.

Si trasladamos a costos estos porcentajes, en la construcción del cuarto redondo, en unidades de costo (8) que toman el precio del $\mathrm{m}^{2}$ de muro como base y debido a que esta solución demanda un incremento del $10,00 \%$ de la superficie de muros, la comparación resulta así: solución a) la losa maciza cuesta 70,24 u.c., mientras que la solución b) de bóveda diptera cuesta 57,02 u.c., con ello la solución alternativa cuesta 18,82 por ciento menos y ofrece un incremento espacial del 21 por ciento.

(8) Las unidades de costo (u.c.) son parte instrumental de un modelo de análisis de los proyectos por su posibilidad económica, desarrollado en el documento "En torno a la tesis del gran galpón": Carlos González Lobo. Materiales Didácticos, Facultad de Arquitectura, UNAM, 1987 

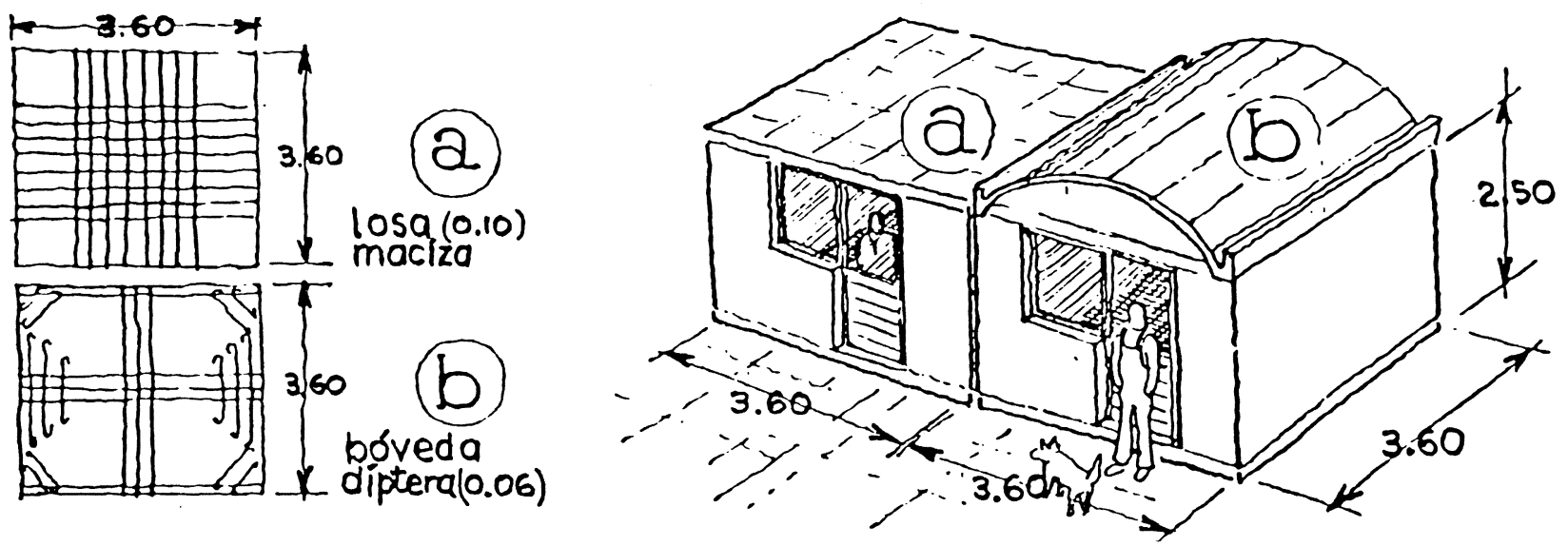

\begin{tabular}{|c|c|c|c|c|}
\hline \multirow{6}{*}{$\begin{array}{l}\text { COMPARACION } \\
\text { ENTRE LOS } \\
\text { MACIZA } \\
\text { BOVEDA DIPTERA }\end{array}$} & conceptos: & $a$-losa macizo & b.bóveda díptera & ahorro enta bóveda: \\
\hline & $\begin{array}{l}\text { suelo.cimiento } \\
\text { dalopros } \\
\text { dacerimetral }\end{array}$ & igual & igual & 0 \\
\hline & concreto $f^{\prime} 200$ & $1.29 \mathrm{~m}^{3}$ & $0.85 \mathrm{~m}^{3}$ & $-0.44 m^{3} \rightarrow-34.1 \%$ \\
\hline & dcero estruc. & $84.21 \mathrm{~kg}$ & $48.40 \mathrm{~kg}$ & $-35.81 \mathrm{~kg} . \rightarrow-42.5 \%$ \\
\hline & muro tímpano & 0 & $3.63 \mathrm{~m}^{2}$ & $+3.63 m^{2} \rightarrow+10.00 \%$ \\
\hline & cimbra & nec.pora $12.96 \mathrm{~m}^{2}$ & $\begin{array}{l}14.18 \mathrm{~m}^{2} \text { met. desplegado } \\
3 v i a a s \text { y } 6 \text { puntales }\end{array}$ & equiv. $-8.5 m^{2}+-65.58 \%$ \\
\hline & volumen habitable & $32: 40 \mathrm{~m}^{3}$ & $38.91 \mathrm{~m}^{3}$ & $+6.51 m^{3} \rightarrow+21 \%$ \\
\hline
\end{tabular}

2. argumento: La tesis del Gran Galpón. Con objeto de ampliar la comprensión del procedimiento propuesto, mostraré un ejemplo de su aplicación a la proyección arquitectónica.

La pregunta implicita en toda obra para los usuarios pobres es: ¿Cuál es la solución arquitectónica-constructiva con más capacidad habitable y el menor costo de inversión inicial directa? Buscando en esa dirección y frente al rechazo popular a las miniaturizaciones espaciales de la obra de "interés social" institucional, y aplicando esta tecnología de cubiertas de bajo costo y de geometría apropiada a la necesidad, llegué a la solución del "gran galpón": construir en una primera etapa un gran volumen espacial habitable (un "cuartote") que permita posteriores cimientos internos "en seco".

Los límites del problema serian como base el cuarto a) De la primera argumentación: un cuarto de 3,60×3,60 metros, con 2,50 m de altura, del que conocemos: superficie útil, volumen habitable y costo en unidades de costo; y como límite superior la duplicación de la superficie útil que se logra con la tipologia colonial de taza y plato: un cuarto de doble altura con un tapanco de madera al medio. Esta solución tiene una tradición de uso ininterrumpido en muchas ciudades de Hispanoamérica y su eficacia y arraigo en las zonas centrales la mantiene como una solución aún en uso: las vecindades mexicanas, por ejemplo.

Por tanto la solución estaría entre alguna de las construcciones que sea mayor de 1 piso y menor o igual a 2 pisos; y la cuestión es localizar la alternativa que supere la contradicción implicita: ¿Cuál es la solución que esté más cerca de la superficie y volumen de la tipología de taza y plato, pero cuyo costo inicial lo más cercano al costo de la solución sea un piso?

La solución emprendida en nuestro medio de techumbres inclinadas y crecimientos en tapanco, era la más sugerente. Pero el límite de esta solución está en la in. tersección de la altura mínima habitable y la pendiente de la cubierta por un lado; por el otro que la economía afecta a los costos diferenciales de los muros y la techumbre con una relación de 1:00 u.c., a 2.92 u.c. respectivamente. Por ello la tendencia del diseño me llevó a "hinchar" el techo, lo cual se logra de dos ma. 

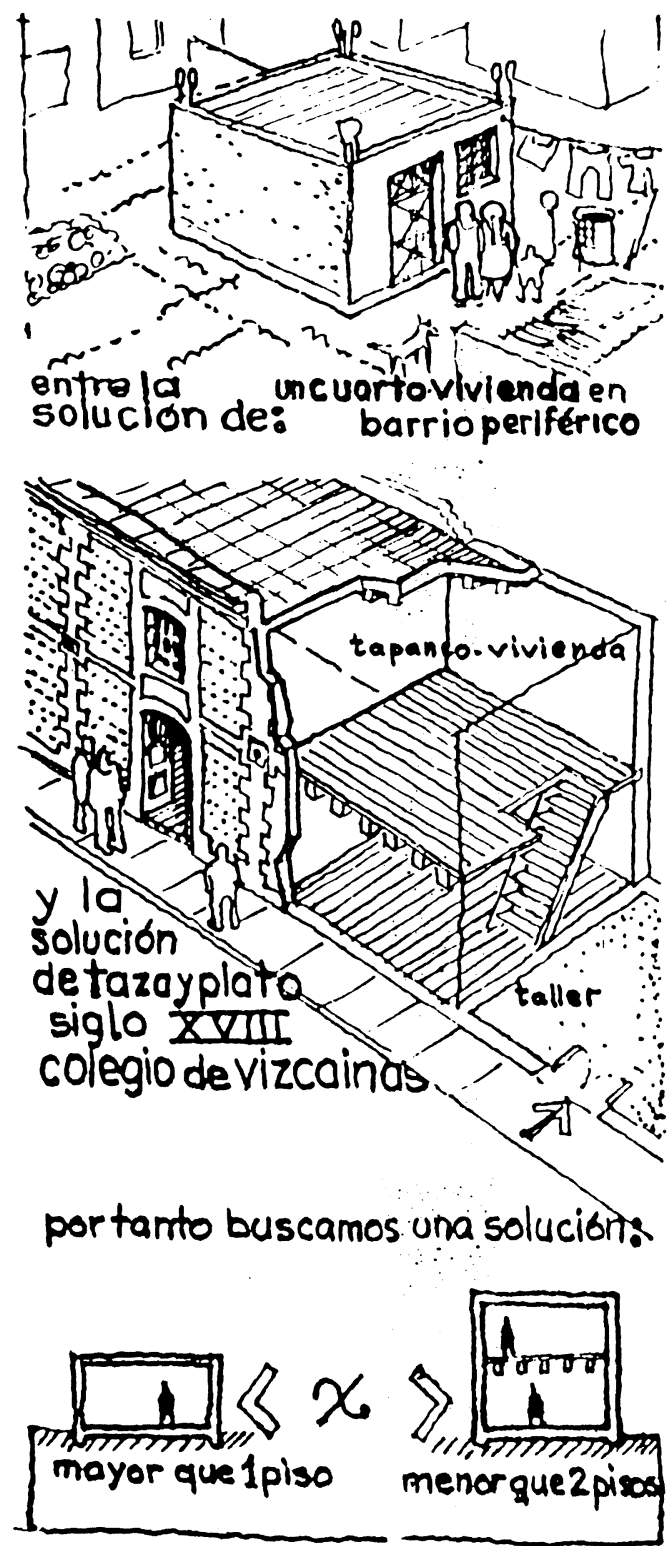

neras: o con una bóveda diptera plena o con una bóveda de cañón esviajada.

Hechos los análisis comparativos de incremento de costo, incremento de superficie-volumen, y tras estudiar en más de 90 alternativas geométricas posibles, resumo el comparativo a los casos más apropiados como se ve en la pág. siguiente.

Del análisis de las soluciones encontramos una respuesta que logra, utilizando la solución del gran galpón: diptera plena o cañón, la obtención de una superficie habitable potencial del doble que la del cuarto base, con una inversión sólo del 22 al $27 \%$ del costo del cuarto inicial. Esta es la solución del gran galpón: que he aplicado desde el conjunto habitacional para Ciudad Sahagún en 1974; que se aplicó en diversos proyectos de vivienda de los talleres de Extensión Univer-
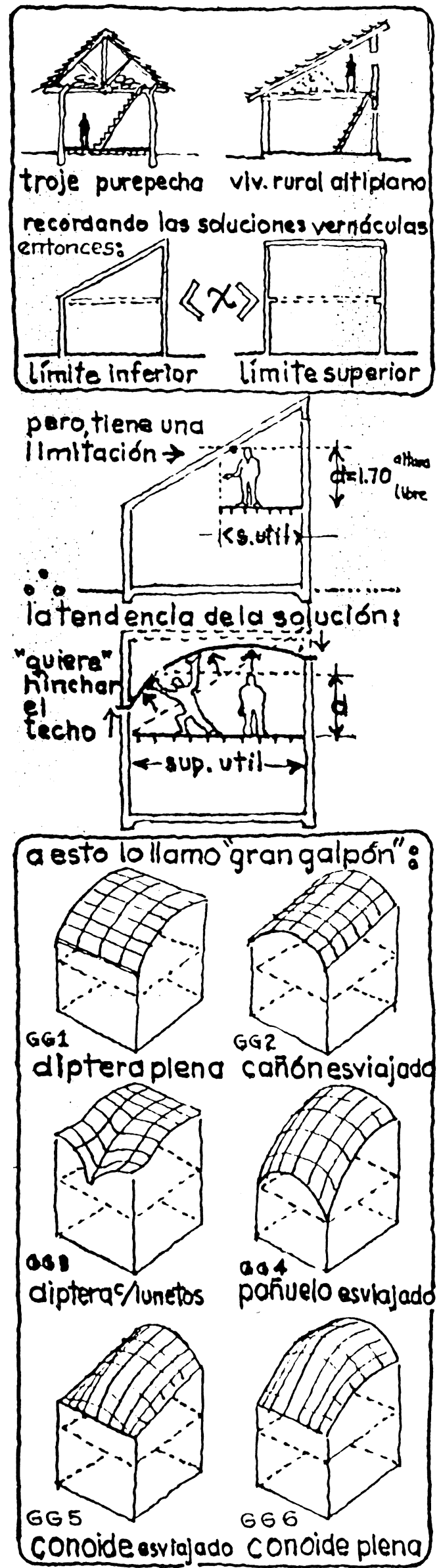


\begin{tabular}{|c|c|c|c|c|c|c|}
\hline comparativo tipos: & Sup.util & Vol.nabit. & Costo U.C. & inc. de/ costo & costg//sup. & costo/vol. \\
\hline 1 piso & $12.96 \mathrm{~m}^{2}$ & & 3.84 u.c. & $\%$ & $5.69 \cup \mathrm{uc} / \mathrm{m}^{2}$ & $2.27 \mathrm{uc} / \mathrm{m}^{3}$ \\
\hline $\begin{array}{l}\text { diptera } \\
\text { plena }\end{array}$ & $25.92 \mathrm{~m}^{2}$ & $n^{3}$ & Bu.c. & $\%$ & $3.62 \mathrm{uc} / \mathrm{m}^{2}$ & 1.4 \\
\hline $\begin{array}{l}\text { cañon } \\
\text { esviajado }\end{array}$ & $25.92 \mathrm{~m}^{2}$ & $60.82 \mathrm{~m}^{3}$ & 0.68 u. . & $2.80 \%$ & $3.49 \mathrm{uc} / \mathrm{mf}$ & $1.50 \mathrm{vc} / \mathrm{m}^{3}$ \\
\hline $\begin{array}{l}\text { taz } \\
\text { pla }\end{array}$ & $25.92 \mathrm{~m}^{2}$ & $m^{3}$ & 840.6 & $5 \%$ & $U G / \mathrm{m}^{2}$ & 1.6 \\
\hline
\end{tabular}

sitaria (TAPEU) del Taller José Revueltas de la Facultad de Arquitectura de la UNAM; y por último, que hemos aplicado para los prototipos de las vecindades que construimos tras el sismo de 1985. Con esta experiencia podemos garantizar que los cálculos son correctos y que la aceptación en 11 años es atractiva para los técnicos y entusiasta de los usuarios.

\section{SISTEMA CGL-2.}

\section{Bóvedas prefabricadas de barro armado.}

La otra alternativa para construir cubiertas de bajo costo que he encontrado, es hacerlas de tabique: de barro o de cemento-arena (tabicón ligero) combinados con acero de refuerzo.

Este método constructivo me lo sugirieron los trabajos de A. Gaudí en la escuelita de la Sagrada Familia, y la obra del Ing. Eladio Dieste en el Uruguay (y las aplicaciones que de su técnica hacen las cooperativas de vivienda uruguayas, y que nos enseñara en 1975 el Arquitecto Luis Lainez). Por ello, desarrollé un sistema constructivo en tabique de barro-armado, que tiene aplicaciones desde la cimentación a las cubiertas; pero en

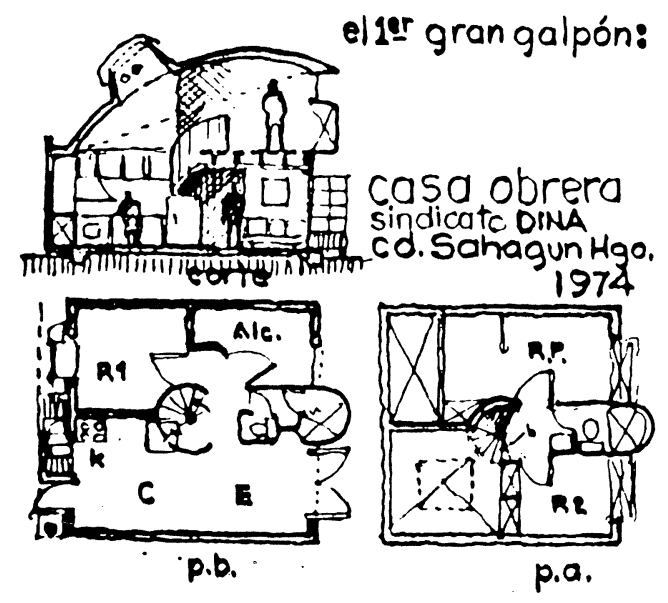

este trabajo sólo voy a exponer la bóveda díptera realizada con este procedimiento.

Las razones mínimas para aplicar el barro armado son las siguientes: el tabique o el tabicón, es el material más usado y conocido en casi todo el mundo; levantar un muro o "pegar tabique" es el procedimiento de construcción más difundido y que requiere mínima calificación especializada. Si además utilizamos el mismo material en muros y cubiertas, la organización y control de materiales se hace más eficiente en procesos de autoconstrucción, y si hacemos piezas prefabricadas apilables a pie de obra, esto permite un ajuste a las características del procedimiento típico de la autoconstrucción; $y$ además, si usamos moldes colectivos que permitan incorporar mano de obra ampliada: mujeres, niños, ancianos, se incrementa la potencialidad productiva de la fuerza de trabajo disponible. 

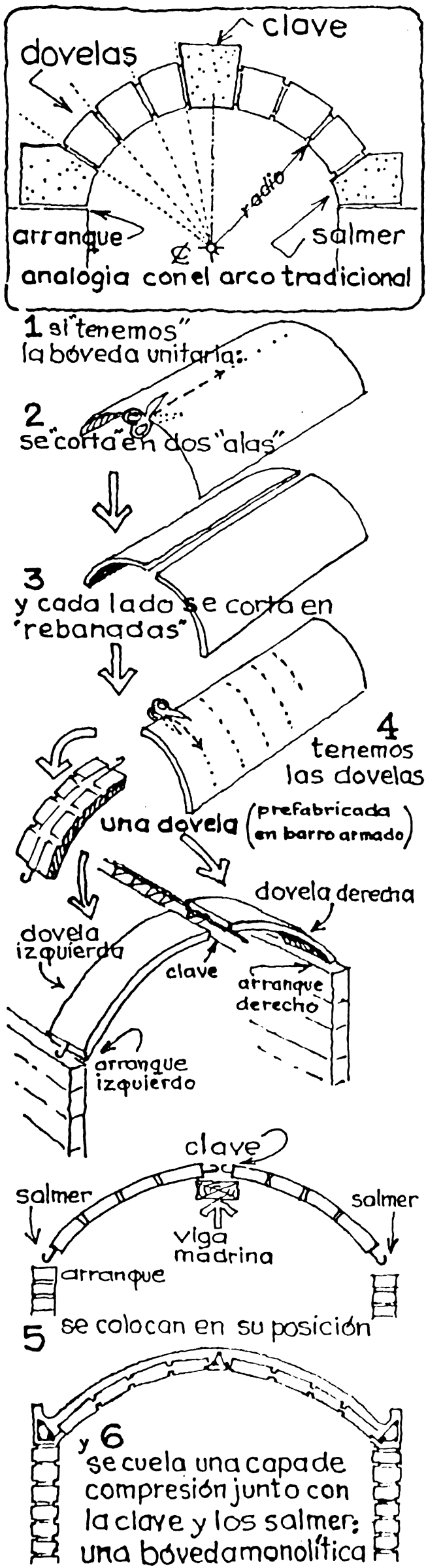

La solución para construir la bóveda parte de imaginar el cañón de la bóveda y cortarlo a la mitad a lo largo, por la generatriz de la "cima", a la que llamaremos clave; y que de cada uno de los brazos (dipteros) de la bóveda los descompongamos a su vez en cortes por las directrices, con bandas cilíndricas como "plintos", a los que por analogía con el arco de la estereotomía llamaré dovelas (una dovela que va del arranque [salmer] a la clave).

Estas dovelas se prefabrican en el suelo, sobre un molde: dejando previsiones para unirlas en la bóveda mediante colados de hormigón armado, que logren una bóveda cilíndrica monolítica.

La dovela está compuesta por dos hileras de tabique (en capuchino) en torno a una junta de hormigón de 0,04 metros. Una varilla de 5/16" que, en la dirección de las generatrices, tiene los tabiques alineados dejando entre las calles de 0,03 m, en que se aloja un "torzal" de alambre recocido de 3 hilos.

\section{Descripción del procedimiento de construcción}

- Se calcula o determina la curvatura conveniente o deseada, pero con una relación cuerda-flecha no menor de 1:8 y la más económica de 1:4 (la más armoniosa, para el usuario sentado, es para $3,60 \mathrm{~m}$ de cuerda, la de 1:3,33).

- Se coloca el trazo sobre el piso y se ajusta a una distribución de los tabiques, dejando para la clave una sección de 0,10 de ancho.

- Se doblan varillas sobre ese trazo, tanto para las dovelas como para hacer unas cerchas de varilla.

- Con las cerchas sobre el suelo, se rellena con tierra o cascajo hasta moldear la sección cilíndrica de la bóveda, menos $3 \mathrm{~cm}$; éstos se aplanan con mezcla de cemento-arena 1:6, y se afinan con reglas, de cercha a cercha. A esto lo llamamos el "burro" y se puede hacer del largo necesario, y aun varios burros, con pasillos para trabajar con comodidad entre ellos en obras muy grandes.

- Para hacer las dovelas, se colocan sobre el burro papeles de bolsa de cemento húmedos, para servir de separadores. Se alinean los tabiques de cada dovela, poniéndoles piedrecillas como separadores. Se arman primero los torzales de alambre retorcido y después las varillas; se cuelan las juntas. Se dejan 6 dias, mojándolas para su curado. Se retiran las piezas entre dos personas y se apilan.

- Teniendo los muros con la cadena perimetral y construidos los tímpanos, se deja un mechinal en 


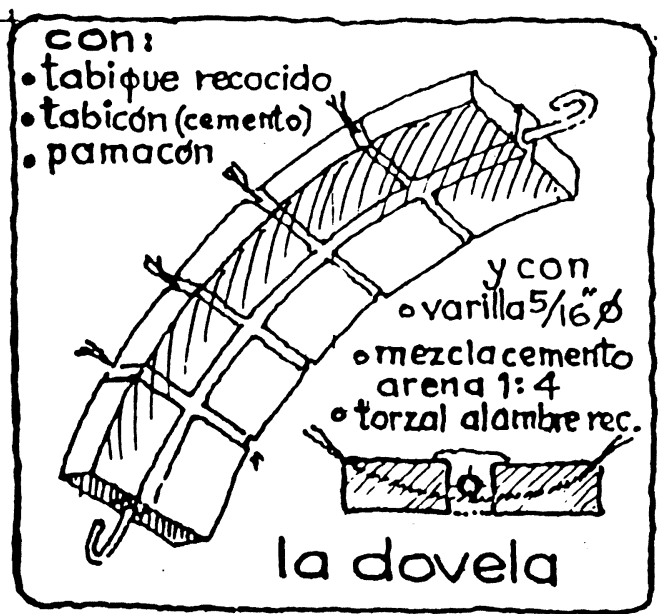

trazo: entre $1 / 2$ y $1 / 8$ del claro
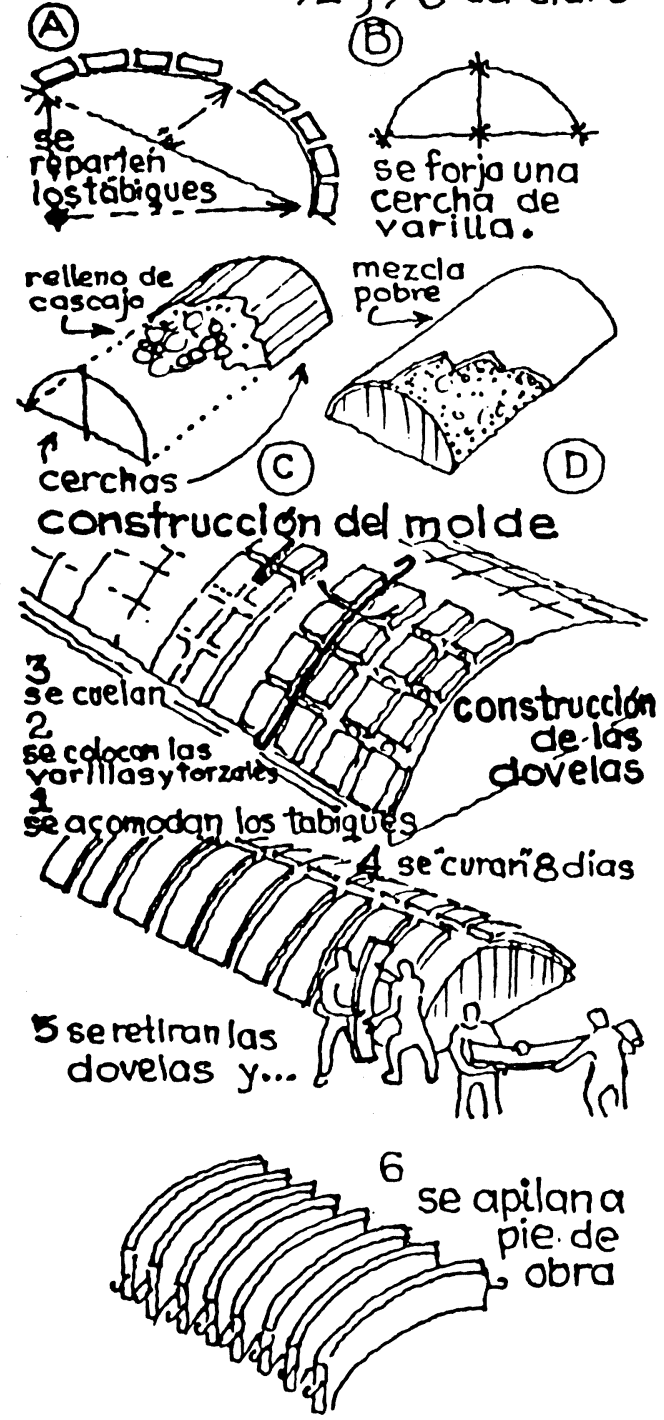

\section{PROCEDIMIENTO DE}

PREPABRICACION

POPULAR COOPERATIVA

SISTEMA

bóvedas de barro armado la cima de cada uno y por ella se pasa una viga de $0,10 \mathrm{~m} \times 0,20 \mathrm{~m}$ con un puntal o dos en su longi. tud, y contraventeados; se coloca la armadura de la cadena-clave y se izan las dovelas apoyándolas sobre la viga y sobre la cadena-salmer, y se retuercen los torzales de alambre para unir todas las piezas. Se coloca sobre la superficie terminada una malla electro-soldada (10.10) y se cuela integralmente: los salmeres, la bóveda y la clave, rellanándose además la junta entre las dovelas que hemos taponado con polyducto; y sobre la bóveda con una capa de 0,03 $\mathrm{m}$ de espesor.

Se procede a curarla como una losa de hormigón, y la viga central (madrina) se puede retirar a los 6 días.

Con este sistema de cubiertas hemos techado no sólo viviendas populares, en que al cañón cerrado lo hemos abierto con lucarnas, o previsiones de crecimiento con paso removible para la escalera; sino que las hemos realizado en gran galpón, con dos "claves"; y actualmente las aplicamos a cubiertas en dientes de sierra para áreas productivas.

Pero también con las mismas piezas se pueden construir bóvedas torales de doble curvatura, o bóvedas "gausas" como las del Ing. Eladio Dieste, que actualmente intentamos para el Centro Social del Mirasol, Es. tado de México.

Este procedimiento se ha utilizado además de en programas de apoyo a la vivienda popular en la ciudad de México, San Juan del Río, Qro., y en comunidades rurales del Estado de México y Tabasco, en la construcción de edificios comunales que requieren de claros mayores, por ejemplo en San Mateo son de 4,50 m $\times$ $14,00 \mathrm{~m}$, en el mercado de "Las Rocas" son de 4,50 $\times$ $6,00 \mathrm{~m}$, y en la Iglesia de Xico, Mex. cada cubierta es de 4,50 $\times 9,00 \mathrm{~m}$. Estas estructuras sufrieron el sismo de 1985 sin presentar ningún daño, pese a las diferencias de suelo en los 3 casos. Además hemos podido constatar que el sistema funciona igual con el uso del tabique de barro, el tabicón ligero de cemento-arena o el uso de tabiques de pamacon (panel de madera y cemento), por lo que podemos señalar que la versatilidad a los materiales disponibles se cumple aquí como tecnología apropiada.

En cuanto al costo, si usamos la convención de las u.c. (unidades de costo comparativo), si un muro de tabique cuesta 1:00, y la losa maciza cuesta 2,92 u.c., la bóveda de hormigón s/metal desplegado nos cuesta 1.90 unidades de costo comparativo y la de barro armado cuesta 1,48 u.c.; los argumentos del apartado anterior son igualmente legítimos aquí. Tanto en el gran galpón. como en la comparación entre losa plana y bóveda, la razón de usar uno u otro sistema es que si hay que emplear mano de obra calificada, la bóveda de barro re- 


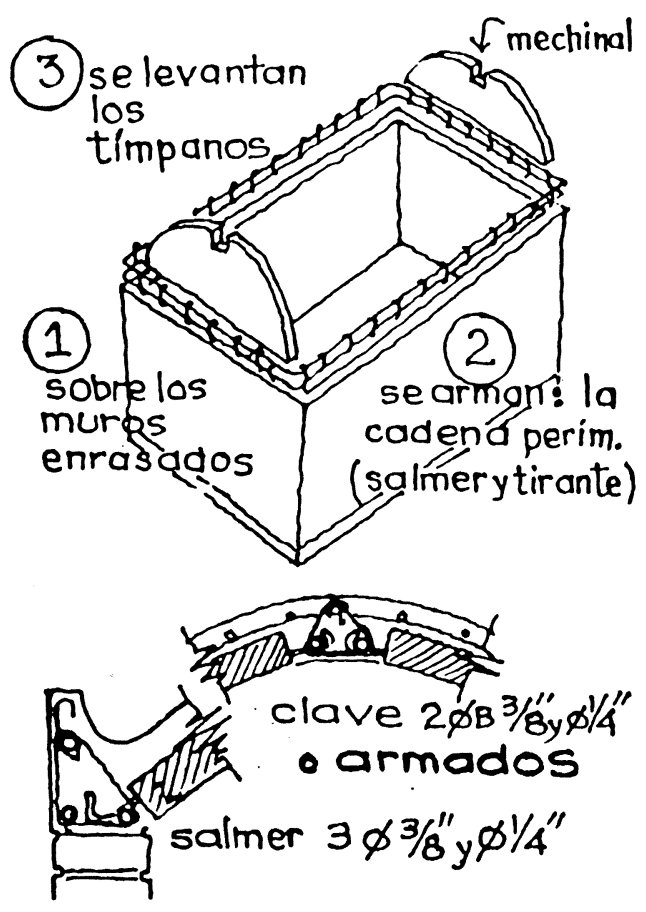

sobre los mechinales

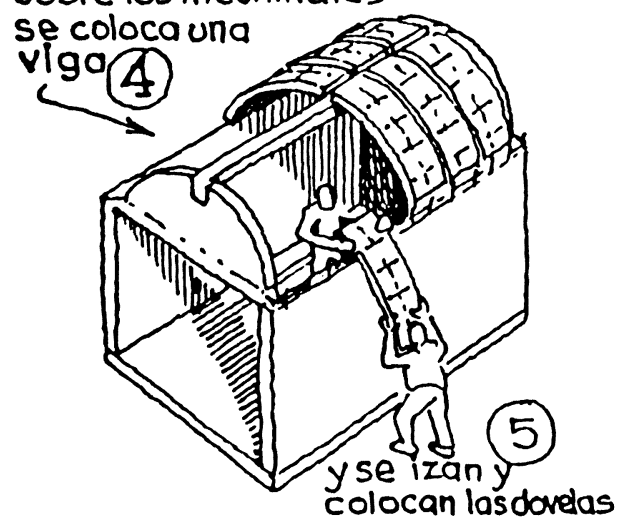

(6) se omarran los torzales y
se coloca una malla $10 \cdot 10$

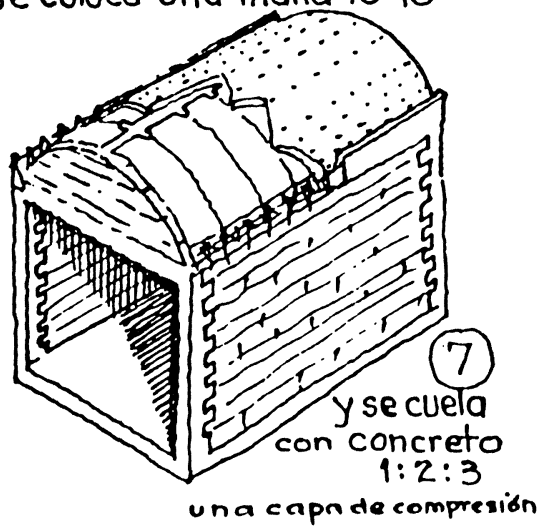

PROGEDIMIENTO

CON STRUCTIVO

DE LAS BOVEDAS SISTEMA

BOVEDAS CGL-2

bóvedas de barroarmado cimBra

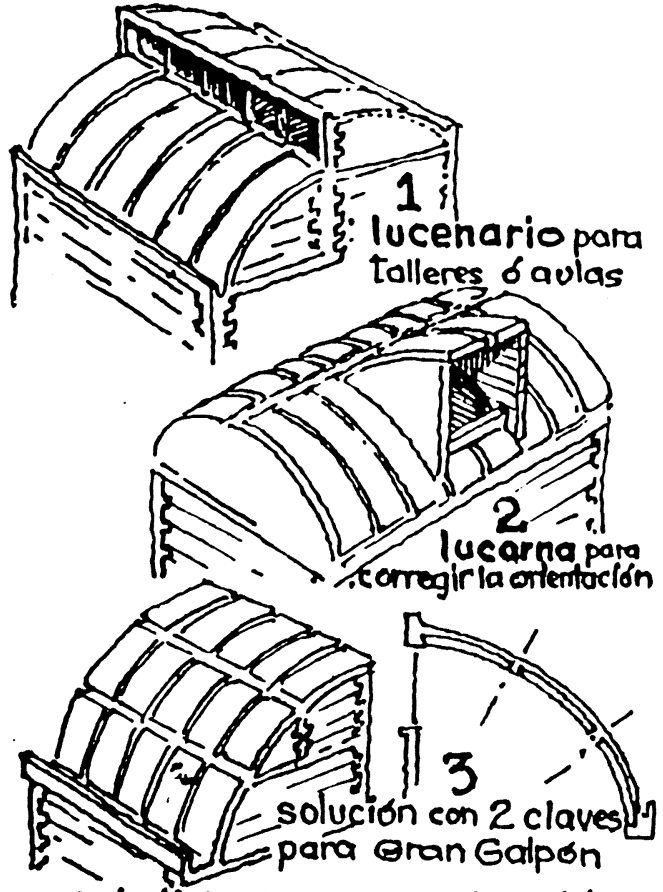

modalidades de aplicación de la bóveda de aovelas -IsTEM CGL-2
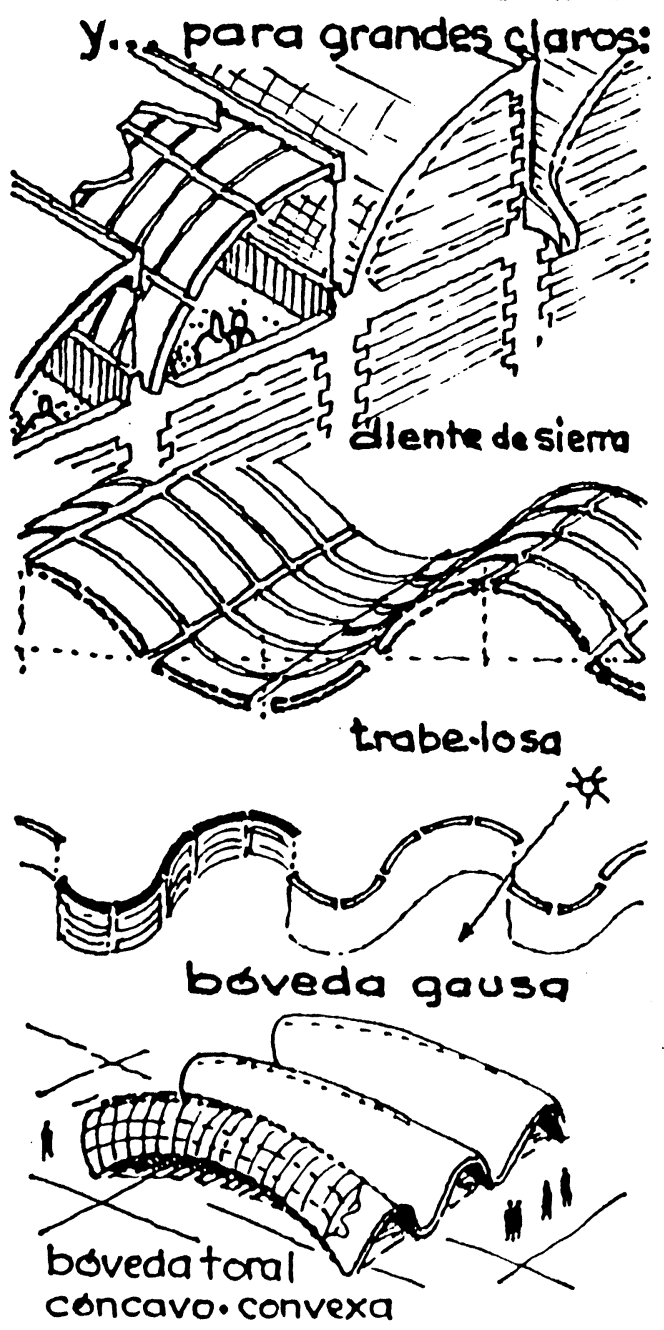
quiere de más horas-hombre que la de metal desplegado; es entonces, más cara; pero si hay población dispuesta al trabajo solidario, entonces el sistema de prefabricación popular cooperativa de barro armado es el sistema más apropiado y sin competencia en costo.

Procedo ahora brevemente a describir experiencias en las que se han aplicado e investigado estas propuestas tecnológicas, como segunda parte de este trabajo.

\section{La viga "T" y la solución al entrepiso plano}

Como una de las demandas que nos hacen los usuarios son los entrepisos planos, he buscado una alternativa apropiada en barro-armado: la viga " $T$ " combinada con dovelas casi planas, prefabricadas.

La viga $T$ me permite tomar la compresión con los tabiques y por el patín vertical de tabique alejar el acero, para incrementar el momento de inercia de la pieza.

- Se construye con el mismo criterio anterior pero colocando la pieza invertida sobre una cama de arena de $0,10 \mathrm{~m}$ de espesor; en ella se coloca una cadena de anillos triangulares isósceles con la separación de 1 tabique para cada anillo y en las cabezas de la viga se colocan piezas de 3/4, 1/2 y $1 / 4$ de tabique para acercar los anillos de refuerzo al cortante.

- Se colocan sobre la superficie de la arena los dos tabiques horizontales (al hilo) y entre ellos un torzal de alambre recocido, juntándolos con mezcla de cemento-arena 1:6; así mismo el corazón entre los dos tabiques, del ancho de 1 tabique.

- Sobre el colado se paran tabiques verticales entre los anillos y se juntan con mezcla 1:6.

- En la cima del anillo triangular se coloca una varilla de $\varnothing 1 / 2$ " y en los $3 / 5$ centrales del claro se agrega una varilla de $\varnothing 3 / 8$ " como refuerzo (esto para claros hasta de $3,60 \mathrm{~m}$ ) y sobre el tabique se cuela en redondo hasta cubrir el acero con mezcla; así mismo se recubren los laterales de los anillos que sobresalen en los ángulos de la $\mathrm{T}$ entre los tabiques.

- Se cura la pieza durante 8 días y se voltea.

- Para hacer el entrepiso se usan dovelas como las del apartado anterior, con una flecha mínima de 1/10 y una longitud máxima de $1,50 \mathrm{~m}$. Ello nos da una separación entre las vigas $T$ de $1,75 \mathrm{~m}$.

- Las dovelas se ligan con las varillas superiores de los anillos triangulares de la viga $T$ y se amarran entre ellas con los torzales de alambre.

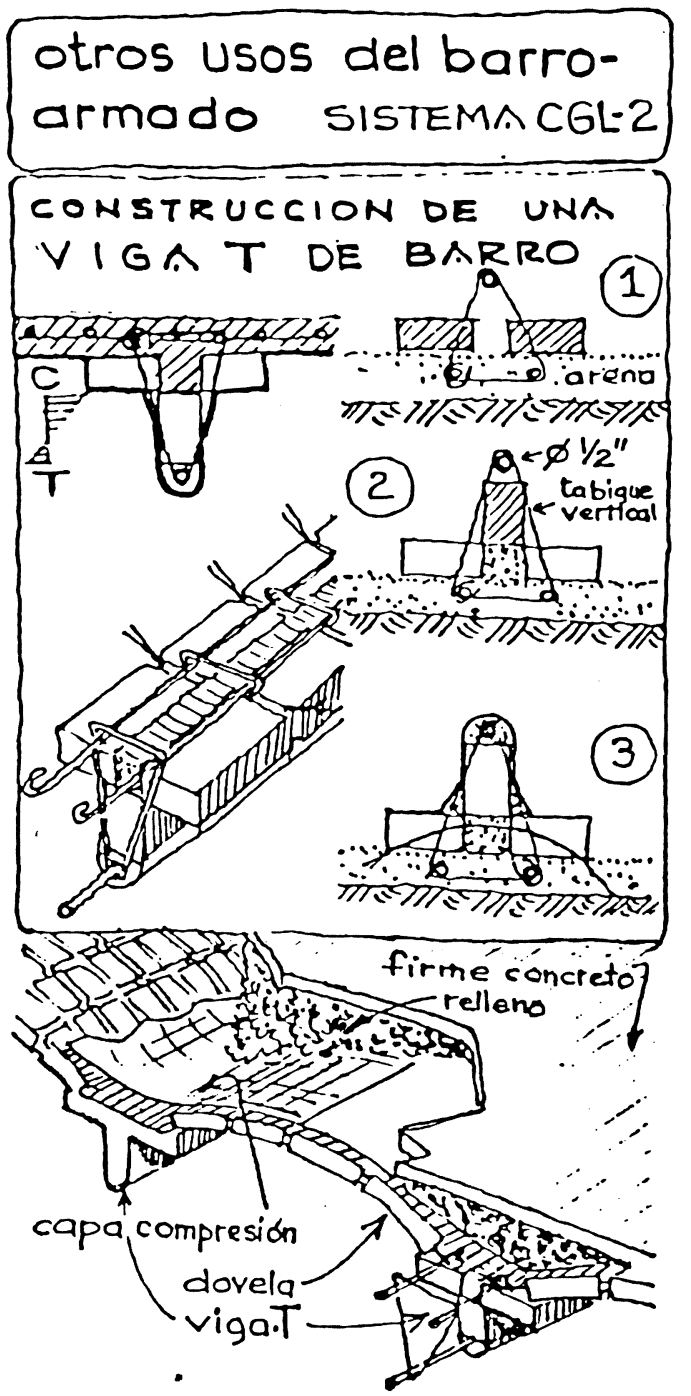

Entrepiso Plano de vigasT y dovelas de $1 / 10$ de flecha
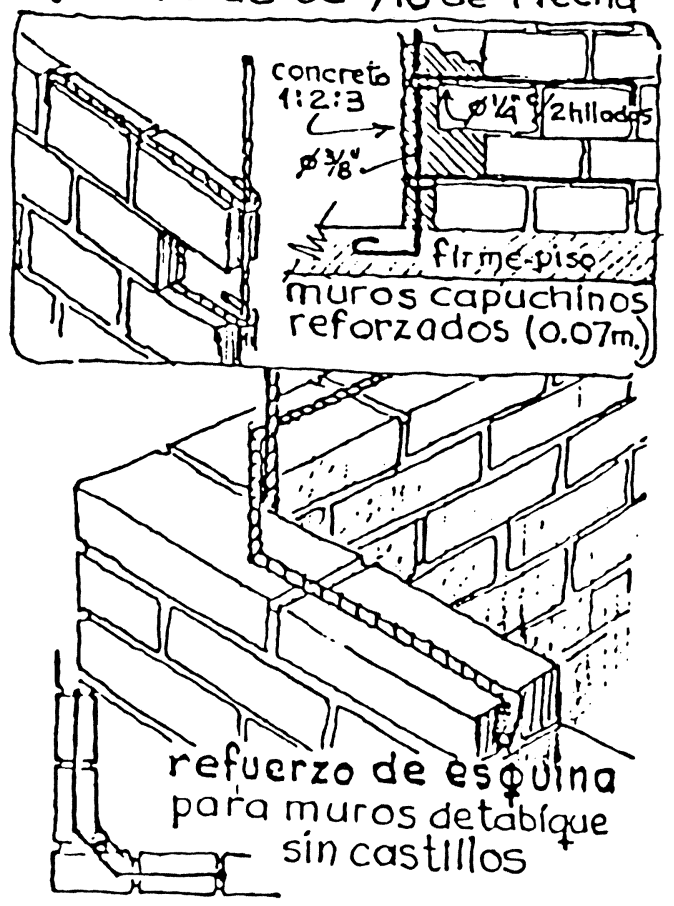

http://informesdelaconstruccion.revistas.csic.es 
- Se cuela la capa de compresión de 0,03 m encima de las dovelas y que llene los anillos y las variIlas con un recubrimiento de $0,02 \mathrm{~m}$, se cura durante 2 días y se aplica el relleno de tezontle (piedra volcánica espumosa o ligera) y se cubre con una capa firme de hormigón de 0,04 metros.

\section{Otras aplicaciones: El Tabique Reforzado}

Por último en este documento quiero consignar algunas aplicaciones que, en la arquitectura popular, permiten reforzar con acero estructural mínimo a los muros de tabique o tabicón.
Las soluciones son una gran variedad. En los dibujos anoto dos muy usuales:

- Los muros capuchinos reforzados con alambrón de $\varnothing 1 / 4$ " para realizar mamparas de separación de 0,06 metros de espesor.

- Los refuerzos para esquinas de muros de tabique o columnas de tabique que con una varilla vertical y ligas de alambrón logran marcos de suficiente rigidez a los cortantes del sismo.

Podriamos anotar otros usos de las tabletas y dovelas de tabique e incluso las soluciones estructurales con ladrillo y fierro de fleje, pero la brevedad de este artículo nos hace terminarlo aquí.

\section{SISTEMA CGL-1}

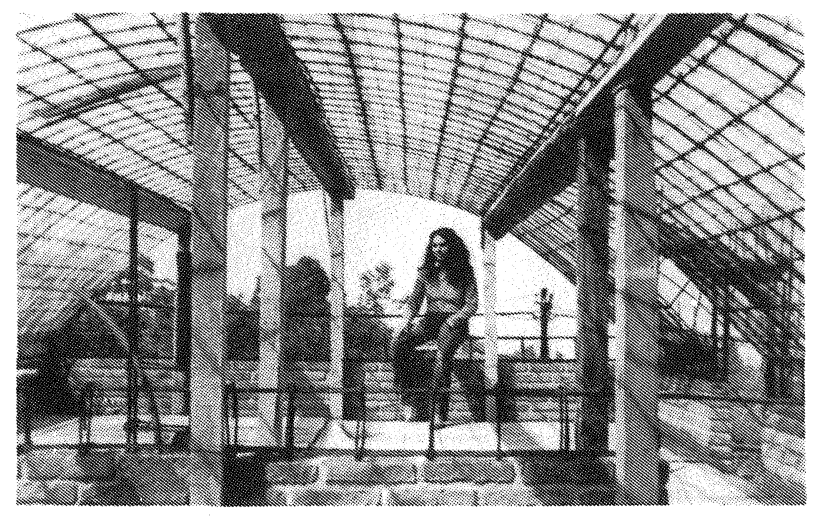

\section{LA BOVEDA DIPTERA PREPARADA PARA EL COLADO}

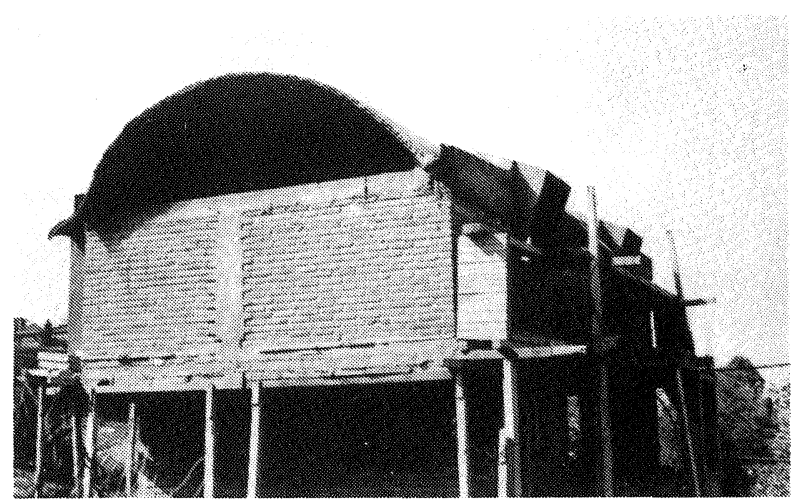

SIST. GRAN GALPON:

CASA HAEITACION EN SN.MIGUEL AJUSCO Arp.ma Eugenia Hurtado $A$. 1983 


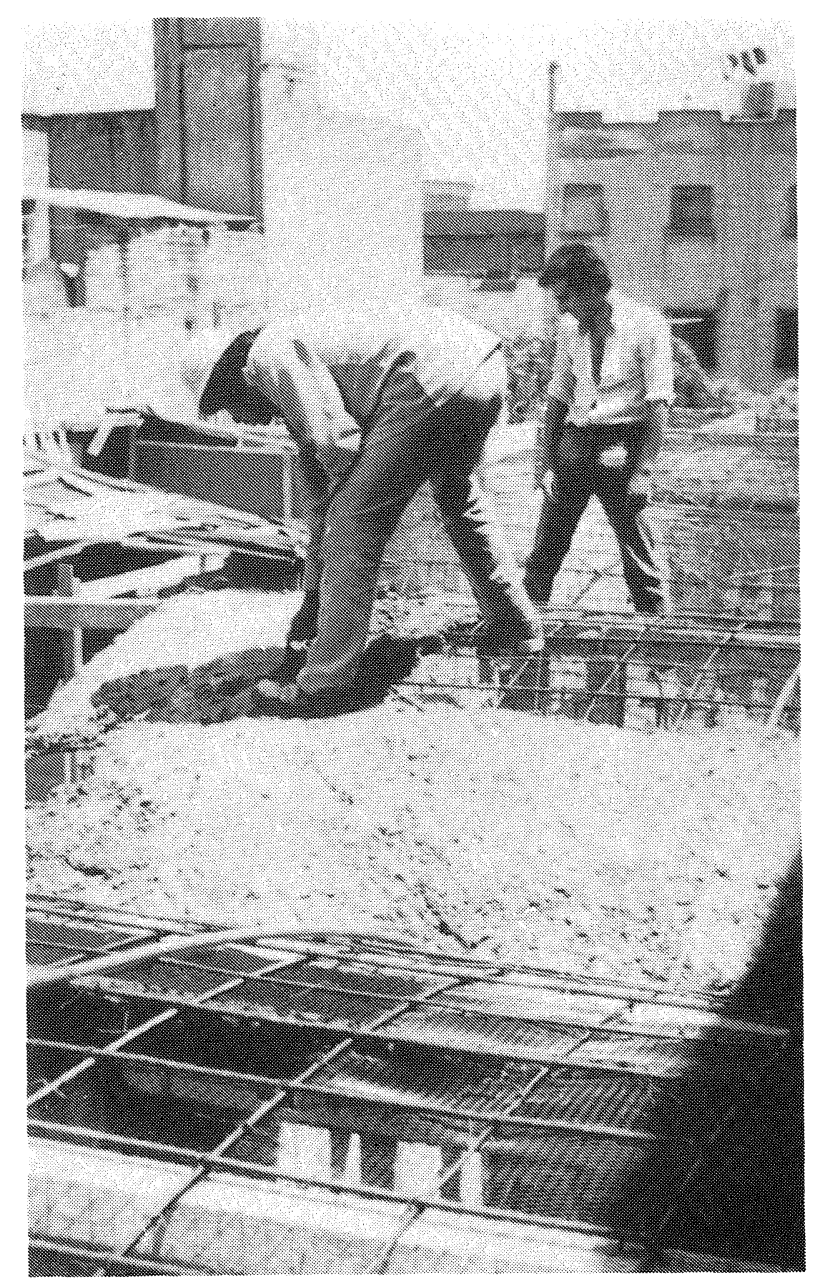

ORUPO PILOTO:

- ESTEBAN MONTEJO

- JUAN MARTIN RANGEL

- braullo hebNANDez

- Fidel dernade R.

- ROOELIO C. LOPEE

- Arestrio pemez.

asesor: C. GZLZ.1080

de la Brigada Solidaria del

tAlLLER nutogestivo jove

COLADO DE LAS

U.N.AM

BOVEDAS DE LA

VECINDAD DE

PINTORES \# 86

Col.morelos Mex.DF.

COLOCACION DEL

METAL DESPLEGADO EN EL

ARMADO DELA

BOVEDA DE LA

IGLESIA DE

SN.JUNN DEL RIO

Sn. MateoThaltenango D.F.

Taller Autogestivo JOSE

REVUELTAS

U. N.A.M.

Asesores C. GONZANEZLOBO

MARIO HERNANDEZ

MIRIAMTABACANIK

1982.87

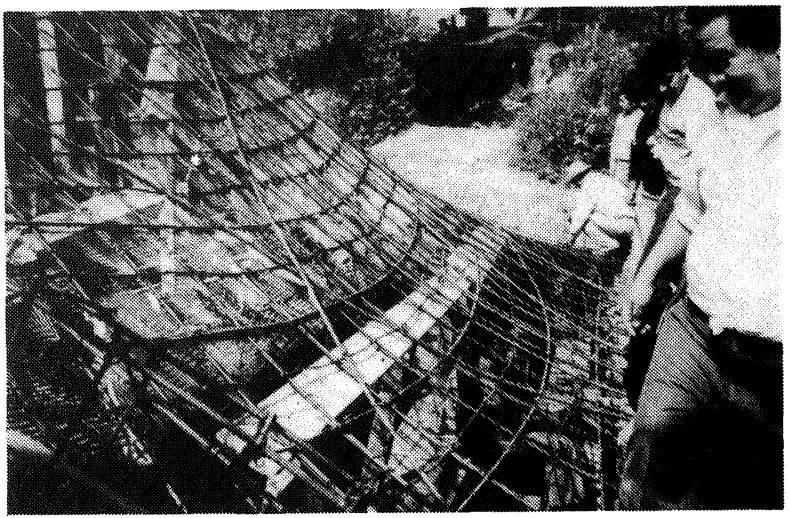



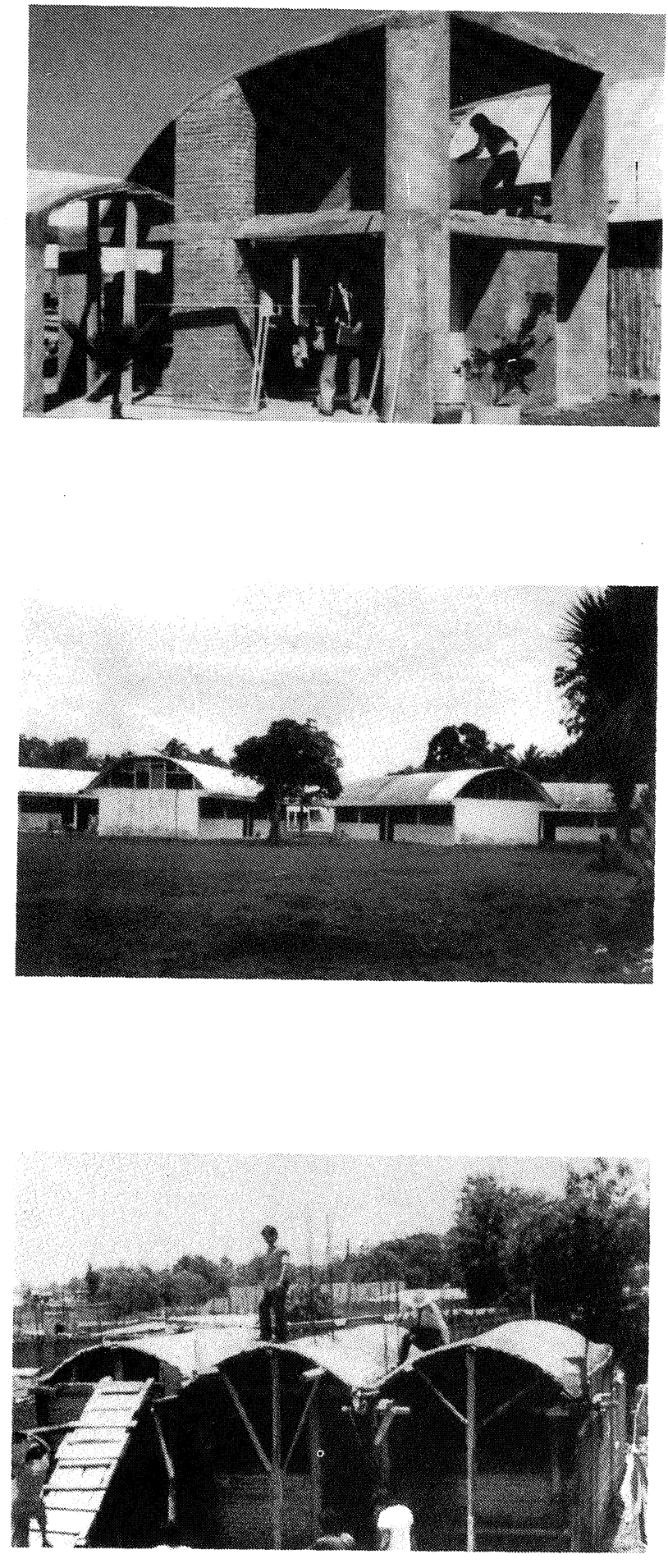

taller JOSEREVUELTAS UNAM. OBRA DEL TAPEU DE XALPAN DiF. ARDS. RODOLFO GOMEZNRIAS BENJAMIN BECERRA P.

1983 


\section{SISTEMA CGL-2}

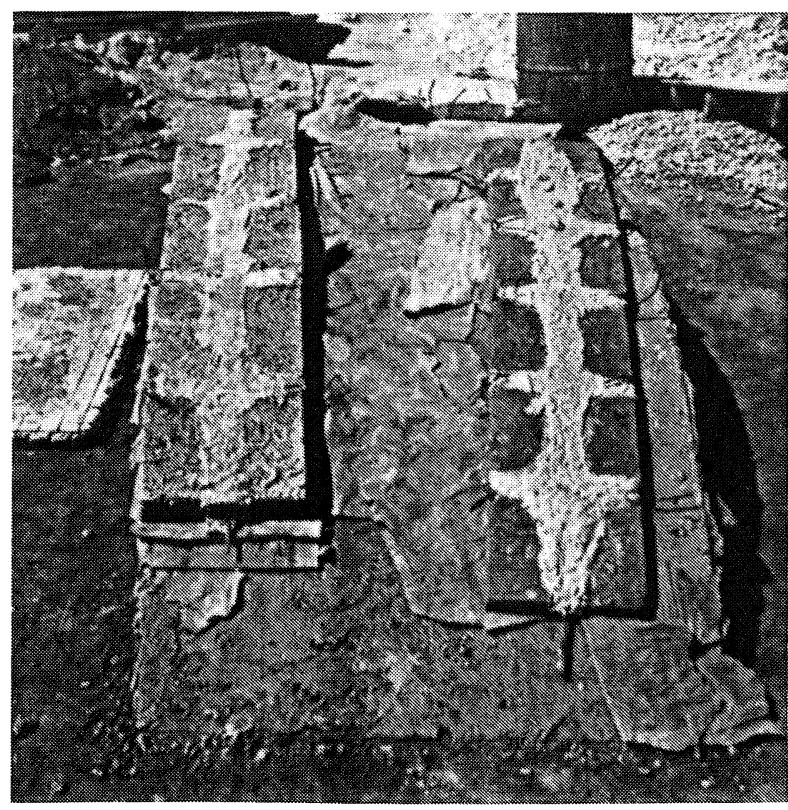

PRUEBAS PARA CONSTRUIR DOVELAS DE TRBIDUE DE BARRO Y TABICON LIGERO DE CEMENTO

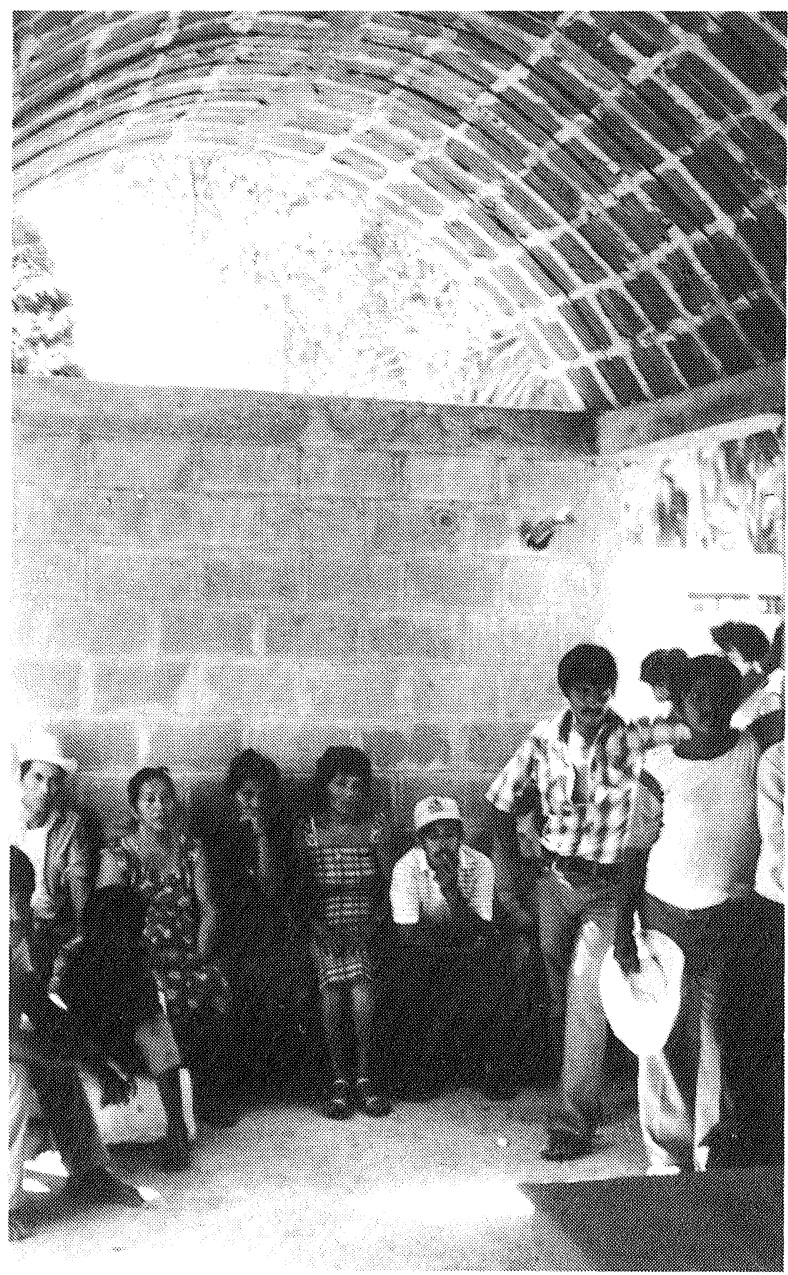

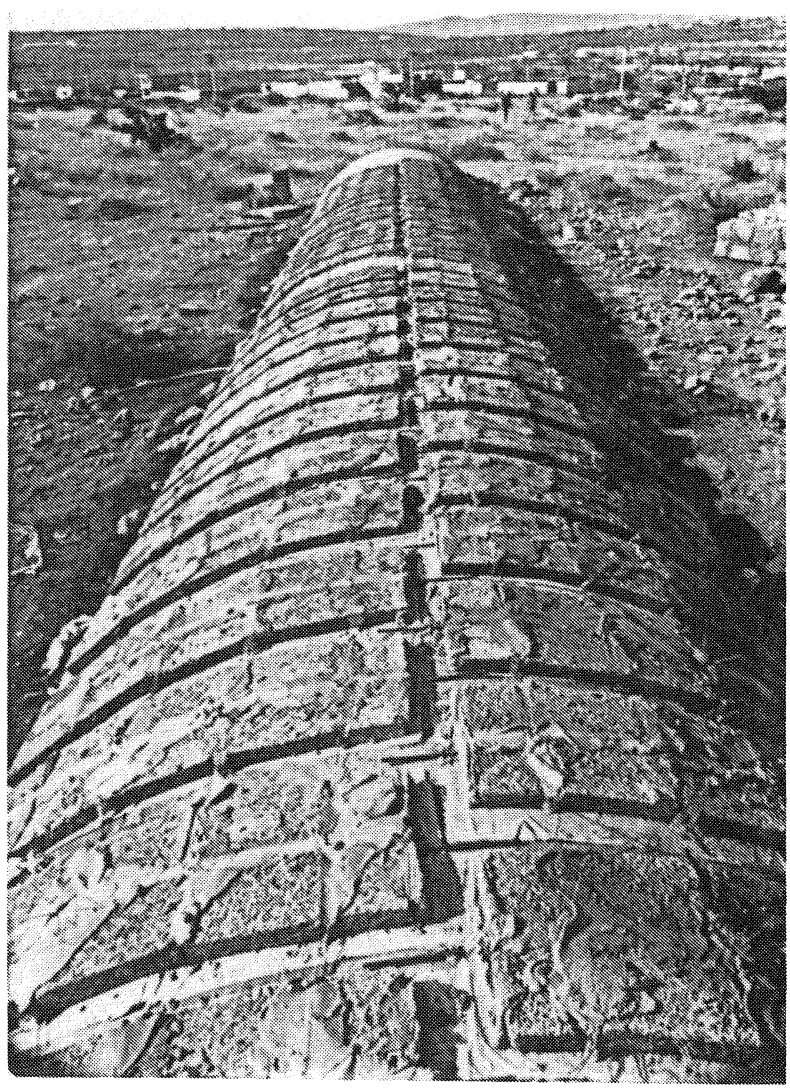

$$
\begin{aligned}
& \text { EL GRAN BURRO } \\
& \text { PREFABRICACION } \\
& \text { DE DOVELAS EN } \\
& \text { ELPEDREGOSO, } \\
& \text { SAN JUNN DELRIO } \\
& \text { DUERETARO } \\
& \text { (TABI ФUES DE PAMKCON) }
\end{aligned}
$$

INVITAB

PROGRAMA DE APOYO

A LA AUTOCONSTRUICCION

CHILAPA, TABASCO

PROTOTIPO DELA

VIVIENDA DE"DOS OJOS".

APLICANDO LA TECNOLOGIS.

DEL BARRO ARMADO.CGL-2.

AROSI CARLOS GONZALRZLOBO

MARISELA CABANAAS

VISTR DEL INTERIOR

DE LA. ESTANCW.COMEDOR 


\section{COLOCACION DE LAS DOVELAS SOBRE LA VIGA MADRINA}

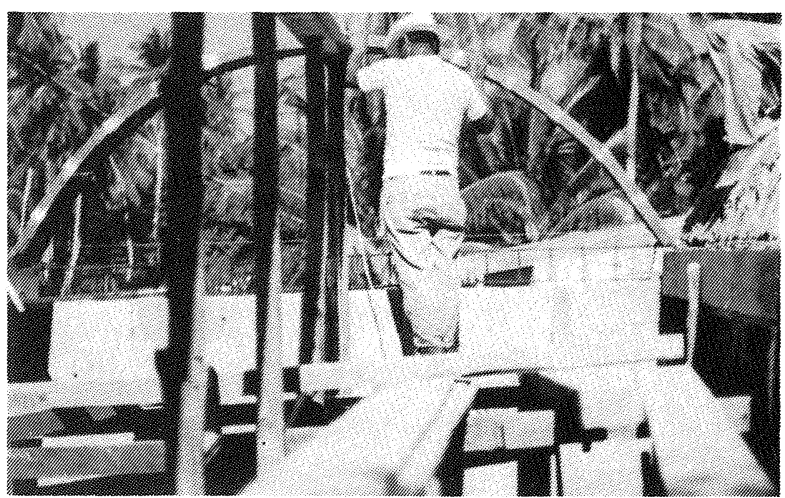

\section{CONSTRUCCION DE BOVEDAS DE DOVELAS JUNTEANDO CON POLYDUCTO PARA UNIRLAS DOVELAS DE PAMACONARMADO}

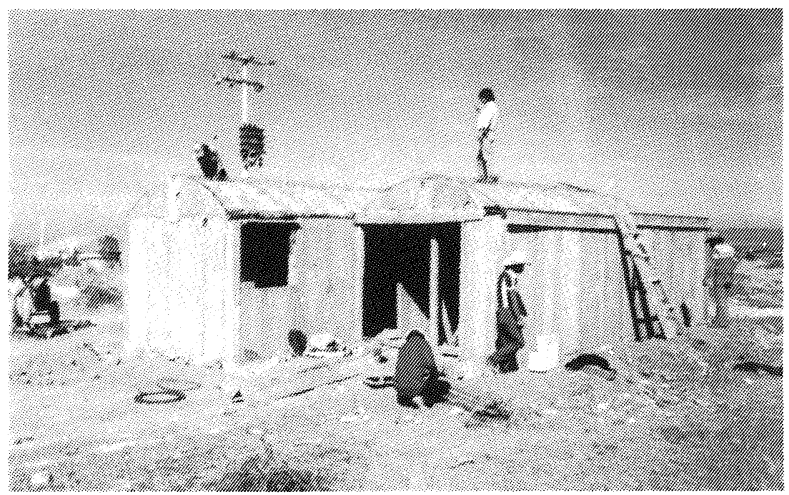

\section{publicación del i.e.t.c.c.}

\section{ACUEDUCTOS ROMANOS EN ESPAÑA Carlos Fernández Casado}

Prof. Dr. Ing. de Caminos, Canales y Puertos

Esta publicación se compone de una serie de artículos, publicados en la Revista "Informes de la Construcción", en los cuales se hace un análisis de los acueductos romanos que existen en España y el balance de las condiciones de conservación en que se encuentra cada uno de ellos, incluyendo referencias históricas y literarias. Se ha ilustrado con la reproducción de la valiosa documentación gráfica que posee el prestigioso autor.

Un volumen encuadernado en couché, a dos colores, de $21 \times 27$ centímetros, compuesto de 238 páginas, numerosos grabados, dibujos, fotos en blanco y negro y figuras de linea.

Precio: España, 1.500 ptas., 21 \$ USA.

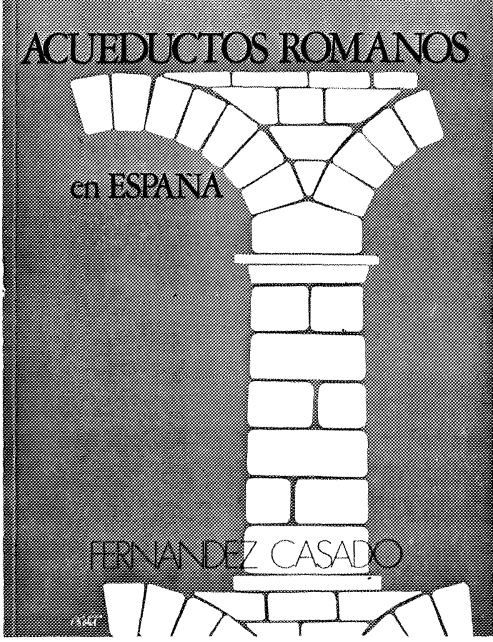

